Supporting Information

\title{
Heterogeneous Hydroxyl-Directed Hydrogenation: Control of Diastereoselectivity through Bimetallic Surface Composition
}

\author{
Alexander J. Shumski, William A. Swann, Nicole J. Escorcia, Christina W. Li* \\ Department of Chemistry, Purdue University, 560 Oval Dr., West Lafayette, Indiana 47907, USA \\ *Corresponding Author: christinawli@purdue.edu
}

1. Materials

2. Catalyst Synthesis Methods

3. Substrate Synthesis Methods

4. Catalytic Hydrogenation Methods

5. Physical Characterization Methods

6. Additional Figures and Data 


\section{Materials}

Palladium(II) nitrate hydrate (37.0-42.0\% Pd), cobalt(II) nitrate hexahydrate (99\%), zinc nitrate hexahydrate (98\%), ammonium hydroxide (28-30\% w/w\%), tetrahydrofuran ( $\geq 99.9 \%)$, anhydrous ethyl ether (BHT stabilized, $\geq 99 \%$ ), pentanes ( $\geq 98 \%$ ), cyclohexane $(\geq 99.0 \%$ ), methylene chloride ( $\geq 99.5 \%$ ), methanol ( $\geq 99.9 \%$ ), (-)-terpinen-4-ol ( $\geq 97 \%$, sum of enantiomers), (S)(-)-limonene (97\%), anhydrous sodium thiosulfate pentahydrate $(\geq 99.5 \%)$, sodium sulfate $(\geq 99.0 \%)$, ammonium chloride ( $\geq 99.5 \%$ ), sodium bicarbonate ( $\geq 99.7 \%$ ), sodium hydride (ca $60 \%$ dispersion in oil), and magnesium turnings were purchased from Thermo Fisher Scientific. Iron(III) nitrate nonahydrate (98\%), aluminum oxide (99\%), nickel(II) nitrate hexahydrate (98\%), 1,5cyclooctadiene(pyridine)(tricyclohexylphosphine)iridium(I) hexafluorophosphate (99\%), lithium aluminum hydride ( $\geq 97 \%$ ), isophorone ( $\geq 97 \%$ ), n-decane (99\%), and titanium(IV) oxide (catalyst support 1/8" pellets) were purchased from Alfa Aesar. Copper(II) nitrate hemi(pentahydrate) (98\%), iodomethane (contains copper as stabilizer, 99\%), silica gel high-purity grade (Davisil Grade 636, pore size $60 \AA, 35-60$ mesh particle size), silica gel high-purity grade (Davisil Grade 636, pore size $60 \AA, 200-425$ mesh particle size), silica gel high-purity grade (Davisil Grade 646, pore size $150 \AA$, 35-60 mesh particle size), (-)-carveol ( $\geq 97 \%$, mixture of isomers), 3-methyl-2cyclohexen-1-ol ( $\geq 96 \%)$, 4-methylanisole (99\%), and lithium sticks for synthesis were purchased from Sigma-Aldrich. Sodium borohydride (99\%) and anhydrous oxalic acid (98\%) were purchased from Acros Organics. Piperitone (mixture of enantiomers, predominately (R)-(-)-form, >94\%) was purchased from Tokyo Chemical Industry. Vulcan XC-72R carbon black was purchased from Fuel Cell Store. Forming gas $\left(5 \% \mathrm{H}_{2} / 95 \% \mathrm{~N}_{2}\right.$ gas mixture) and hydrogen (99\%) gas cylinders were purchased from Indiana Oxygen. Anhydrous ammonia (99.99\%) was purchased from Matheson Gas. SiliaFlash P60 (40 - $63 \mu \mathrm{m}, 60 \AA$ ) was purchased from Silicycle. Dideuterium (99.8\% D, 99.6\% $\mathrm{D}_{2}$ ) and deuterated chloroform (99.8\%) were purchased from Cambridge Isotope Laboratories and the deuterated chloroform was stored over $\mathrm{Na}_{2} \mathrm{CO}_{3}$ prior to use. 


\section{Catalyst Synthesis Methods}

\section{$\mathrm{Pd}_{3} \mathrm{M} / \mathrm{Al}_{2} \mathrm{O}_{3}(\mathrm{M}=\mathrm{Fe}, \mathrm{Co}, \mathrm{Ni}, \mathrm{Cu}, \mathrm{Zn})$}

A representative procedure is provided for the synthesis of $\mathrm{Pd}_{3} \mathrm{Cu} / \mathrm{Al}_{2} \mathrm{O}_{3}$ by incipient wetness impregnation. Palladium nitrate hydrate $(62.5 \mathrm{mg}, 0.235 \mathrm{mmol})$ and copper nitrate hemipentahydrate $(18.2 \mathrm{mg}, 0.078 \mathrm{mmol})$ are dissolved in $250 \mu \mathrm{L}$ nanopure water. The solution is added dropwise, with vigorous mixing between each addition, to $500 \mathrm{mg}$ of 200 mesh aluminum oxide. The brown powder is then dried overnight at $80{ }^{\circ} \mathrm{C}$ and calcined at $400{ }^{\circ} \mathrm{C}$ for 2 hours in air. The black calcined powder is then reduced under a flow of $5 \% \mathrm{H}_{2} / 95 \% \mathrm{~N}_{2}$ at $60-100 \mathrm{~mL} / \mathrm{min}$ in a tube furnace at $800{ }^{\circ} \mathrm{C}$ for 1 hour. The resulting powder is stable indefinitely when stored under $\mathrm{N}_{2}$.

For all other $\mathrm{Pd}_{3} \mathrm{M} / \mathrm{Al}_{2} \mathrm{O}_{3}$ catalysts, the appropriate metal nitrate hydrate is utilized during the coimpregnation. For pure $\mathrm{Pd} / \mathrm{Al}_{2} \mathrm{O}_{3}$, only the palladium nitrate hydrate is impregnated. To catalyze the semihydrogenation of limonene, a $\mathrm{Pd}_{1} \mathrm{Cu}_{1} / \mathrm{Al}_{2} \mathrm{O}_{3}$ is prepared using the same method.

\section{$\mathrm{Pd}_{3} \mathrm{Cu} / \mathrm{SiO}_{2} 800 \mathrm{~N}_{2}-400 \mathrm{H}_{2}$ and Thermal Treatment Variants}

Following a modified literature procedure, a palladium tetrammine precursor is prepared by dissolving palladium nitrate hydrate $(248 \mathrm{mg}, 1 \mathrm{mmol})$ in $1.75 \mathrm{~mL}$ of $\mathrm{H}_{2} \mathrm{O}$ followed by dropwise addition of $2.0 \mathrm{~mL}$ of $30 \% \mathrm{NH}_{4} \mathrm{OH}$ solution, yielding a brown suspension with approximate $\mathrm{pH}$ of 11. Separately, a copper ammine precursor solution is prepared by dissolving copper nitrate hemipentahydrate $(77.5 \mathrm{mg}, 0.33 \mathrm{mmol}$ ) in $1.75 \mathrm{~mL}$ of water followed by dropwise addition of 2.0 $\mathrm{mL}$ of $30 \% \mathrm{NH}_{4} \mathrm{OH}$, yielding a dark blue solution.

The $3.75 \mathrm{~mL}$ palladium tetrammine solution is added dropwise, with vigorous mixing in between each addition, to $5 \mathrm{~g}$ of Davisil 636 silica and sonicated briefly. The impregnated silica is dried overnight in air at $120{ }^{\circ} \mathrm{C}$ to form a white powder and subsequently calcined in air at $500{ }^{\circ} \mathrm{C}$ for 3 hours to yield a black $\mathrm{PdO}_{x} / \mathrm{SiO}_{2}$ powder. The $3.75 \mathrm{~mL}$ copper ammine solution is next added dropwise to the $\mathrm{PdO}_{\mathrm{x}} / \mathrm{SiO}_{2}$, dried at $120{ }^{\circ} \mathrm{C}$ in air overnight, and calcined at $400{ }^{\circ} \mathrm{C}$ in air for 2 hours. The powder is annealed at $800{ }^{\circ} \mathrm{C}$ in $\mathrm{N}_{2}$ for 1 hour, cooled to room temperature, and reduced at $400{ }^{\circ} \mathrm{C}$ in $5 \% \mathrm{H}_{2} / 95 \% \mathrm{~N}_{2}$ at $60-100 \mathrm{~mL} / \mathrm{min}$ for 1 hour. The sample was exposed to air for 2-3 hours prior to storage in an $\mathrm{N}_{2}$ glovebox.

For variants on the thermal treatments of $\mathrm{Pd}_{3} \mathrm{Cu} / \mathrm{SiO}_{2}$ shown in Table 1, we vary the temperature and sequence of the $\mathrm{N}_{2}$ annealing and $5 \% \mathrm{H}_{2} / \mathrm{N}_{2}$ reduction steps carried out in the tube furnace. All thermal treatment steps are performed for 1 hour. To synthesize pure $\mathrm{Pd} / \mathrm{SiO}_{2}$, the $\mathrm{PdO} \mathrm{X}_{\mathrm{x}} / \mathrm{SiO}_{2}$ powder is reduced in-situ in pure $\mathrm{H}_{2}$. 


\section{Large Pore (150 А) $\mathrm{Pd}_{3} \mathrm{Cu} / \mathrm{SiO}_{2}$}

Palladium tetrammine precursor is prepared by dissolving palladium nitrate hydrate (140 $\mathrm{mg}$, $0.564 \mathrm{mmol}$ ) in $1.75 \mathrm{~mL}$ of $\mathrm{H}_{2} \mathrm{O}$ followed by the rapid injection of $1.75 \mathrm{~mL} 30 \% \mathrm{NH}_{4} \mathrm{OH}$, yielding a pale yellow solution with an approximate $\mathrm{pH}$ of 13. Separately, a copper ammine precursor solution is prepared by dissolving copper nitrate hemipentahydrate $(43.7 \mathrm{mg}, 0.188 \mathrm{mmol})$ in 1.75 $\mathrm{mL} \mathrm{H}_{2} \mathrm{O}$ followed by the addition of $1.75 \mathrm{~mL} \mathrm{30 \%} \mathrm{NH}_{4} \mathrm{OH}$, yielding a dark blue solution.

The $3.50 \mathrm{~mL}$ palladium tetrammine solution is added dropwise, with vigorous mixing in between each addition, to $3.00 \mathrm{~g}$ of Davisil 646 silica and sonicated briefly. The impregnated silica is dried overnight in air at $120{ }^{\circ} \mathrm{C}$ to form a white powder and subsequently calcined in air at $500{ }^{\circ} \mathrm{C}$ for 3 hours to yield a black $\mathrm{PdO}_{x} / \mathrm{SiO}_{2}$ powder. The $3.50 \mathrm{~mL}$ copper ammine solution is next added dropwise to the $\mathrm{PdO}_{\mathrm{x}} / \mathrm{SiO}_{2}$, dried at $120{ }^{\circ} \mathrm{C}$ in air overnight, and calcined at $400{ }^{\circ} \mathrm{C}$ in air for 2 hours. The powder is annealed at $720{ }^{\circ} \mathrm{C}$ in $\mathrm{N}_{2}$ for 1 hour, cooled to $400{ }^{\circ} \mathrm{C}$ over 40 minutes and reduced at this temperature in $5 \% \mathrm{H}_{2} / 95 \% \mathrm{~N}_{2}$ at $60-100 \mathrm{~mL} / \mathrm{min}$ for 1 hour. The sample is rapidly cooled to room temperature and exposed to air for 2-3 hours prior to storage in an $\mathrm{N}_{2}$ glovebox. The resulting powder is stable indefinitely when stored under $\mathrm{N}_{2}$.

\section{$\mathrm{Cu} / \mathrm{SiO}_{2}$}

A copper tetrammine precursor solution was prepared by dissolving copper nitrate hemipentahydrate $(73.2 \mathrm{mg}, 0.315 \mathrm{mmol})$ in $0.750 \mathrm{~mL}$ of $\mathrm{H}_{2} \mathrm{O}$ followed by the addition of 0.550 $\mathrm{mL} 30 \% \mathrm{NH}_{4} \mathrm{OH}$. The dark blue solution was added dropwise to $1.00 \mathrm{~g}$ Davisil 646 silica with vigorous mixing and sonicated briefly, then dried overnight at $120{ }^{\circ} \mathrm{C}$ and calcined at $500{ }^{\circ} \mathrm{C}$ in air to give a dark powder. The powder was reduced under a flow of $5 \% \mathrm{H}_{2} / 95 \% \mathrm{~N}_{2}$ at $800{ }^{\circ} \mathrm{C}$ for 1 hour, cooled to room temperature, transferred in air to a vial, and used immediately. 


\section{Substrate Synthesis Methods}

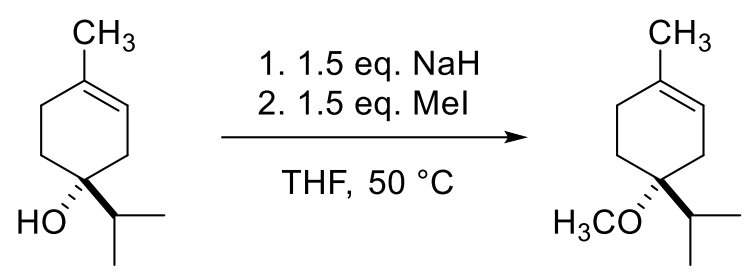

Terpinen-4-ol Methyl Ether. To a flame dried three-neck flask equipped with a reflux condenser was added freshly distilled THF (4.0 mL) and $\mathrm{NaH}(60 \%$ dispersion in mineral oil, $110 \mathrm{mg}, 3.0$ mmol) while purging with nitrogen. Terpinen-4-ol (308 mg, $2.0 \mathrm{mmol})$ in dry THF $(1.5 \mathrm{~mL})$ was added dropwise to the suspension, and the mixture stirred at $50{ }^{\circ} \mathrm{C}$ for $1.5 \mathrm{~h}$. The solution was cooled to room temperature, followed by the addition of MeI ( $426 \mathrm{mg}, 3.0 \mathrm{mmol})$ in dry THF (2.0 $\mathrm{mL}$ ). The solution was again heated to $50{ }^{\circ} \mathrm{C}$ and stirred for $4 \mathrm{~h}$. After cooling to room temperature, the reaction was quenched with saturated $\mathrm{NH}_{4} \mathrm{Cl}(0.5 \mathrm{~mL}), 30 \% \mathrm{Na}_{2} \mathrm{~S}_{2} \mathrm{O}_{3}(4.0 \mathrm{~mL})$, and extracted with diethyl ether $(3 \times 15 \mathrm{~mL})$. The combined organic layers were dried over $\mathrm{Na}_{2} \mathrm{SO}_{4}$ and condensed in vacuo. The residue was purified by silica gel chromatography using hexane:dichloromethane (95:5) eluent to give a clear oil (262 mg, 78\%). ${ }^{1} \mathrm{H}$ NMR (500 MHz, $\left.\mathrm{CDCl}_{3}\right) \delta 5.30-5.26(\mathrm{~m}, 1 \mathrm{H}), 3.16(\mathrm{~s}, 3 \mathrm{H}), 2.12-2.03(\mathrm{~m}, 2 \mathrm{H}), 1.99(\mathrm{sep}, J=6.9 \mathrm{~Hz}, 1 \mathrm{H}), 1.95$ $-1.87(\mathrm{~m}, 1 \mathrm{H}), 1.85-1.78(\mathrm{~m}, 1 \mathrm{H}), 1.78-1.72(\mathrm{~m}, 1 \mathrm{H}), 1.67(\mathrm{~s}, 3 \mathrm{H}), 1.60(\mathrm{ddd}, J=13.9,12.0$, $5.5 \mathrm{~Hz}, 1 \mathrm{H}), 0.88(\mathrm{dd}, J=8.1,6.9 \mathrm{~Hz}, 6 \mathrm{H}) .{ }^{13} \mathrm{C}$ NMR $\left(126 \mathrm{MHz}, \mathrm{CDCl}_{3}\right) \delta 133.98,118.25,76.44$, $48.21,31.57,29.87,27.31,26.91,23.56,17.74,16.60$. These spectroscopic parameters are consistent with literature values. ${ }^{1}$

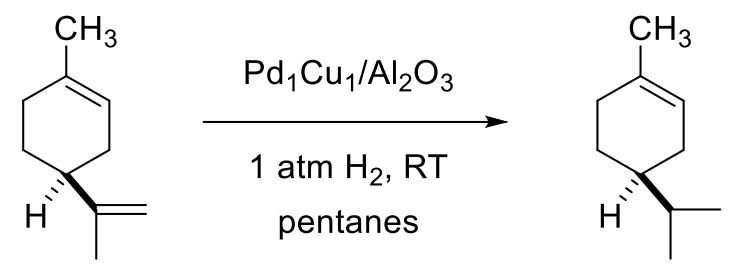

p-Menthene. Limonene $(127 \mathrm{mg}, 0.933 \mathrm{mmol})$ was added to a suspension of $\mathrm{Pd}_{1} \mathrm{Cu}_{1} / \mathrm{Al}_{2} \mathrm{O}_{3}(500$ $\mathrm{mg}, 2 \% \mathrm{w} / \mathrm{w} \mathrm{Pd}, 0.0943 \mathrm{mmol})$ in pentanes $(93.3 \mathrm{~mL})$ and stirred at room temperature under hydrogen balloon pressure for $4 \mathrm{~h}$. The reaction was filtered, washed with pentanes $(3 \times 5 \mathrm{~mL})$, and the filtrate analyzed via gas chromatography prior to condensing in vacuo to give a clear oil ( $86 \%$-menthene by GC). Chromatographic parameters are consistent with literature data (Figure S12) ${ }^{2,3}$ 


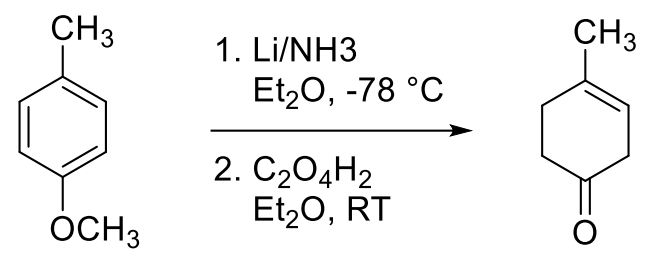

4-methyl-3-cyclohexenone. A solution of 4-methylanisole $(7.33 \mathrm{~g}, 60.0 \mathrm{mmol})$ in anhydrous $\mathrm{Et}_{2} \mathrm{O}$ $(40.0 \mathrm{~mL})$ was added to distilled liquid $\mathrm{NH}_{3}(40.0 \mathrm{~mL})$ at $-78{ }^{\circ} \mathrm{C}$. The flask was purged with dry nitrogen for 30 minutes, followed by the addition of $\mathrm{Li}(2.10 \mathrm{~g}, 300 \mathrm{mmol})$ in small portions over 30 minutes. The deep blue solution was stirred for 10 minutes followed by the careful addition of $\mathrm{MeOH}(12.0 \mathrm{~mL})$. The crude mixture was added to water $(300 \mathrm{~mL})$ and extracted with $\mathrm{Et}_{2} \mathrm{O}(3 \mathrm{x}$ $100 \mathrm{~mL}$ ). The combined organic layers were condensed to $100 \mathrm{~mL}$ and added to a saturated solution of oxalic acid $(9.18 \mathrm{~g}, 101 \mathrm{mmol})$ in water $(50.0 \mathrm{~mL})$. The biphasic mixture was stirred for $12 \mathrm{~h}$ at room temperature, quenched with $\mathrm{NaHCO}_{3}(10.7 \mathrm{~g})$, added to $200 \mathrm{~mL}$ water, and extracted with $\mathrm{Et}_{2} \mathrm{O}\left(3 \times 100 \mathrm{~mL}\right.$ ). The combined organic layers were dried over $\mathrm{MgSO}_{4}$, condensed in vacuo, and purified using silica gel chromatography with hexanes:chloroform (8:2) eluent to give a colorless oil which was found by NMR to contain 14\% 4-methylcyclohexanone (4.97 g, 75\%). ${ }^{1} \mathrm{H}$ NMR (500 MHz, $\left.\mathrm{CDCl}_{3}\right) \delta 5.43(\mathrm{~m}, 1 \mathrm{H}), 2.85-2.80(\mathrm{~m}, 2 \mathrm{H}), 2.50(\mathrm{t}, J=6.9$ $\mathrm{Hz}, 2 \mathrm{H}), 2.40(\mathrm{t}, J=6.8 \mathrm{~Hz}, 2 \mathrm{H}), 1.77(\mathrm{~m}, 3 \mathrm{H}) .{ }^{13} \mathrm{C} \mathrm{NMR}\left(126 \mathrm{MHz}, \mathrm{CDCl}_{3}\right) \delta 210.97,134.88$, $118.41,39.75,38.67,30.45,23.18$. The obtained NMR spectra are in good agreement with previously reported data. ${ }^{4}$

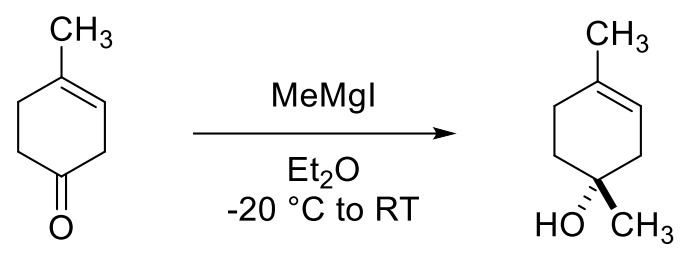

1,4-dimethyl-3-cyclohexenol. A flame dried three-neck flask equipped with a reflux condenser was charged with anhydrous $\mathrm{Et}_{2} \mathrm{O}(5.00 \mathrm{~mL})$ and $\mathrm{Mg}$ turnings $(182 \mathrm{mg}, 7.50 \mathrm{mmol})$. MeI (1.06 g, $7.50 \mathrm{mmol}$ ) was added to the flask and the mixture stirred at room temperature for 30 minutes or until the disappearance of solid $\mathrm{Mg}$. The grey solution was brought to $-20{ }^{\circ} \mathrm{C}$, followed by the dropwise addition of 4-methyl-3-cyclohexenone $(0.550 \mathrm{~g}, 5.00 \mathrm{mmol})$ in anhydrous $\mathrm{Et}_{2} \mathrm{O}(2.00$ $\mathrm{mL}$ ). After addition, the solution was warmed to room temperature and stirred for $12 \mathrm{~h}$ under $\mathrm{N}_{2}$, followed by the addition of saturated $\mathrm{NH}_{4} \mathrm{Cl}(3.00 \mathrm{~mL})$ and $30 \% \mathrm{Na}_{2} \mathrm{~S}_{2} \mathrm{O}_{3}(3.00 \mathrm{~mL})$. The crude mixture was added to water $(20.0 \mathrm{~mL})$ and extracted with $\mathrm{Et}_{2} \mathrm{O}(3 \times 10 \mathrm{~mL})$. The combined organic layers were dried over $\mathrm{MgSO}_{4}$, condensed in vacuo, and purified with silica gel chromatography using hexanes: ethyl acetate (9:1) eluent to give a colorless oil which was found by NMR to contain 5\% 1,4-dimethylcyclohexanol (332 mg, 53\%). ${ }^{1} \mathrm{H}$ NMR (500 MHz, $\left.\mathrm{CDCl}_{3}\right) \delta 5.29(\mathrm{~m}, 1 \mathrm{H}), 2.18$ - $1.93(\mathrm{~m}, 4 \mathrm{H}), 1.72-1.64(\mathrm{~m}, 4 \mathrm{H}), 1.61-1.56(\mathrm{~m}, 2 \mathrm{H}), 1.25(\mathrm{~s}, 3 \mathrm{H}) .{ }^{13} \mathrm{C}$ NMR $(126 \mathrm{MHz}$, $\left.\mathrm{CDCl}_{3}\right) \delta 133.59,118.89,68.52,39.97,35.57,28.55,28.00,23.39$. The obtained NMR spectra are in good agreement with previously reported data. ${ }^{4}$ 


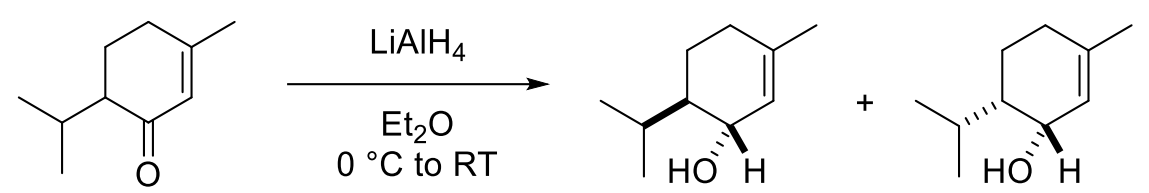

Piperitol. Piperitone $(10 \mathrm{mmol})$ in anhydrous $\mathrm{Et}_{2} \mathrm{O}(6.0 \mathrm{~mL})$ was added dropwise to an ice-cold suspension of $\mathrm{LiAlH}_{4}(417 \mathrm{mg}, 11 \mathrm{mmol})$ in anhydrous $\mathrm{Et}_{2} \mathrm{O}(9.2 \mathrm{~mL}$, subsequently warmed to room temperature and stirred under $\mathrm{N}_{2}$ for $8 \mathrm{~h}$. After the reaction period, the mixture was brought to $0{ }^{\circ} \mathrm{C}$, quenched with acetone $(12 \mathrm{~mL})$, and poured into a vigorously stirred saturated solution of Rochelle's salt $(100 \mathrm{~mL})$ at $0{ }^{\circ} \mathrm{C}$ then stirred at room temperature for $6 \mathrm{~h}$. The crude mixture was extracted with $\mathrm{Et}_{2} \mathrm{O}(3 \times 50 \mathrm{~mL})$ and the combined organic layers dried over $\mathrm{MgSO}_{4}$ and condensed in vacuo. The crude residue was purified with silica gel chromatography using pentanes:chloroform (9:1) eluent to give a pale yellow oil $(1.53 \mathrm{~g}, 99 \%)$ as a mixture of cis/trans diastereomers (26:74) assigned by ${ }^{1} \mathrm{H}$ NMR spectra of the olefinic and alpha-hydroxyl peaks in correspondence with gas chromatography on the mixture. The obtained NMR spectra are in good agreement with previously reported data.,6

Cis-piperitol ${ }^{13} \mathrm{C}$ NMR $\left(126 \mathrm{MHz}, \mathrm{CDCl}_{3}\right) \delta 139.85,123.85,65.21,46.33,31.64,28.55,23.54$, 21.16, 20.96, 20.74.

Trans-piperitol ${ }^{13} \mathrm{C} \mathrm{NMR}\left(126 \mathrm{MHz}, \mathrm{CDCl}_{3}\right) \delta 137.81,125.42,69.30,48.21,30.23,26.72,23.27$, 21.35, 21.06, 17.56.

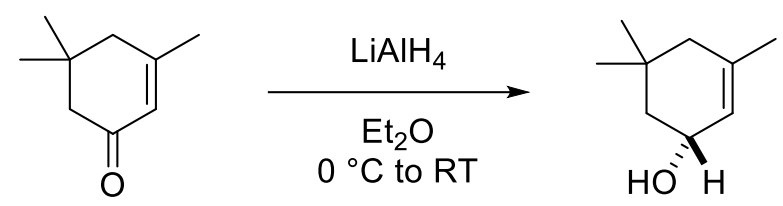

Isophorol. Isophorone $(10 \mathrm{mmol})$ in anhydrous $\mathrm{Et}_{2} \mathrm{O}(6.0 \mathrm{~mL})$ was added dropwise to an ice-cold suspension of $\mathrm{LiAlH}_{4}(417 \mathrm{mg}, 11 \mathrm{mmol})$ in anhydrous $\mathrm{Et}_{2} \mathrm{O}(9.2 \mathrm{~mL}$, subsequently warmed to room temperature and stirred under $\mathrm{N}_{2}$ for $8 \mathrm{~h}$. After the reaction period, the mixture was brought to $0{ }^{\circ} \mathrm{C}$, quenched with acetone $(12 \mathrm{~mL})$, and poured into a vigorously stirred saturated solution of Rochelle's salt $(100 \mathrm{~mL})$ at $0{ }^{\circ} \mathrm{C}$ then stirred at room temperature for $6 \mathrm{~h}$. The crude mixture was extracted with $\mathrm{Et}_{2} \mathrm{O}(3 \times 50 \mathrm{~mL})$ and the combined organic layers dried over $\mathrm{MgSO}_{4}$ and condensed in vacuo. The crude residue was purified with silica gel chromatography using pentanes:chloroform (8.5:1) eluent to give a clear oil (936 mg, 67\%) ${ }^{1} \mathrm{H} \mathrm{NMR}\left(500 \mathrm{MHz}, \mathrm{CDCl}_{3}\right)$ $\delta 5.44-5.39(\mathrm{~m}, 1 \mathrm{H}), 4.26-4.19(\mathrm{~m}, 1 \mathrm{H}), 1.84(\mathrm{~d}, J=17.7 \mathrm{~Hz}, 1 \mathrm{H}), 1.75$ (ddd, $J=12.5,6.1,1.7$ $\mathrm{Hz}, 1 \mathrm{H}), 1.67$ (s, 3H), 1.60 (d, $J=17.3 \mathrm{~Hz}, 1 \mathrm{H}), 1.39$ (br s, 1H), 1.22 (dd, $J=12.4,9.0 \mathrm{~Hz}, 1 \mathrm{H})$, 0.99 (s, 3H), 0.88 (s, 3H). ${ }^{13} \mathrm{C}$ NMR (126 MHz, $\left.\mathrm{CDCl}_{3}\right) \delta 136.21,123.77,67.01,45.42,44.27$, $31.35,31.20,26.37,23.67$. The obtained NMR spectra are in good agreement with previously reported data. ${ }^{7}$ 


\section{Catalytic Hydrogenation Methods}

\section{Hydrogenation using Supported Pd-M Catalysts}

A stock solution of each substrate was prepared at $20 \mathrm{mM}$ in cyclohexane with $10 \mathrm{mM}$ decane or dodecane as an internal standard. No reagents or glassware are dried prior to use, and all reaction set up is carried out in air.

A $20 \mathrm{~mL}$ septum-capped vial is charged with $50 \mathrm{mg}$ of the desired $2 \mathrm{wt} . \% \mathrm{Pd}-\mathrm{M} / \mathrm{SiO}_{2}$ catalyst (10 $\mathrm{mol} \%)$ and $5 \mathrm{~mL}$ of the substrate stock solution $(0.1 \mathrm{mmol})$ in cyclohexane. The solution is purged with $\mathrm{H}_{2}$ for 10 minutes and then stirred under balloon pressure of $\mathrm{H}_{2}$ at room temperature for the desired time. At the end of the reaction, the solution is filtered and analyzed by gas chromatography.

\section{Hydrogenation using Crabtree's Catalyst}

Iridium catalyzed hydrogenation reactions were performed using the method described by Crabtree et. al. ${ }^{8}$ Briefly, terpinen-4-ol $(50 \mathrm{mg}, 0.3 \mathrm{mmol})$ in methylene chloride $(5 \mathrm{~mL})$ was added to a 50 $\mathrm{mL}$ three-neck flask equipped with a flushing adapter connected to a stoppered hydrogen balloon. After three freeze-pump-thaw cycles, the solution was warmed to room temperature and back filled with dry nitrogen followed by the addition of $\left[\operatorname{Ir}(\operatorname{cod})\left(\mathrm{PCy}_{3}\right)(\mathrm{Py})\right] \mathrm{PF}_{6}(6 \mathrm{mg}, 0.0075 \mathrm{mmol})$ as a solid. Immediately, the hydrogen stopper was opened, and the solution stirred at room temperature. After 45 minutes, methylene chloride was removed in vacuo, the crude residue dissolved in diethyl ether $(5 \mathrm{~mL})$ and passed through a $0.2 \mu \mathrm{m}$ PTFE syringe filter to remove precipitated salts. The filtrate was immediately analyzed by gas chromatography.

\section{Deuteration using $\mathrm{Pd}_{3} \mathrm{Cu} @ \mathrm{SiO}_{2}$}

A three-neck flask equipped with a stir bar and a flushing adapter connected to a $\mathrm{D}_{2}$-filled gas expansion bag was charged with terpinen-4-ol $(46.2 \mathrm{mg}, 0.300 \mathrm{mmol})$ in cyclohexane $(5 \mathrm{~mL})$ and $\mathrm{Pd}_{3} \mathrm{Cu} @ \mathrm{SiO}_{2}(150 \mathrm{mg}, 0.03 \mathrm{mmol})$. The solution was frozen in liquid nitrogen, the headspace evacuated and backfilled with dry $\mathrm{N}_{2}$. $\mathrm{D}_{2}$ was introduced into the flask, and the solution stirred at room temperature for $20 \mathrm{~h}$. After this time, the solution was filtered and condensed in vacuo. The crude residue was loaded onto a silica gel plug and eluted with pentanes then methanol to give a white, crystalline solid (51 mg, 107\%).

\section{Deuteration using Crabtree's catalyst}

A flame dried three-neck flask equipped with a stir bar and a flushing adapter connected to a $\mathrm{D}_{2}$ filled gas expansion bag was charged with terpinen-4-ol $(15.4 \mathrm{mg}, 0.100 \mathrm{mmol})$ in anhydrous methylene chloride $(5 \mathrm{~mL})$. The flask was backfilled with $\mathrm{D}_{2}$ and the solution frozen in liquid nitrogen. After three freeze-pump-thaw cycles, the flask was backfilled with dry nitrogen and the 
catalyst added to the thawed solution as a solid. $\mathrm{D}_{2}$ was immediately introduced into the flask, and the solution stirred at room temperature for 45 minutes. After this time, the solution was condensed in vacuo, the crude residue redissolved in $\mathrm{Et}_{2} \mathrm{O}$ and passed through a $0.2 \mu \mathrm{m}$ PTFE syringe filter. The filtrate was condensed in vacuo, the crude residue loaded onto a silica gel plug and eluted with pentanes then methanol to give a white, crystalline solid (11 mg, 69\%).

\section{Kinetics Experiments on $\mathrm{Pd}_{3} \mathrm{Cu} / \mathrm{SiO}_{2}$}

A stock solution of terpinen-4-ol was prepared at $20 \mathrm{mM}$ in cyclohexane with $10 \mathrm{mM}$ decane as an internal standard.

A $100 \mathrm{~mL}$ three-neck flask is charged with $400 \mathrm{mg}$ of $800 \mathrm{~N}_{2}-400 \mathrm{H}_{2} \mathrm{Pd}_{3} \mathrm{Cu} / \mathrm{SiO}_{2}$ and $40 \mathrm{~mL}$ of the stock solution. The solution is purged through with a gas expansion bag containing $\mathrm{H}_{2}$ and then stirred under $\mathrm{H}_{2}$ at room temperature. At specified time points in the reaction, $0.5 \mathrm{~mL}$ aliquots are removed under positive hydrogen pressure. The crude reaction aliquots are analyzed using gas chromatography.

\section{Reinjection Experiments on $\mathrm{Pd}_{3} \mathrm{Cu} / \mathrm{SiO}_{2}$}

A stock solution of terpinen-4-ol was prepared at $20 \mathrm{mM}$ in cyclohexane with $10 \mathrm{mM}$ decane as an internal standard.

A $50 \mathrm{~mL}$ three-neck flask is charged with $150 \mathrm{mg}$ of $800 \mathrm{~N}_{2}-400 \mathrm{H}_{2} \mathrm{Pd}_{3} \mathrm{Cu} / \mathrm{SiO}_{2}$ and $15 \mathrm{~mL}$ of the terpinen-4-ol stock solution $(0.3 \mathrm{mmol})$. The solution is purged through with a gas expansion bag containing $\mathrm{H}_{2}$ and then stirred under $\mathrm{H}_{2}$ at room temperature. After $20 \mathrm{~h}, 1 \mathrm{~mL}$ of a concentrated terpinen-4-ol solution ( $300 \mathrm{mM}, 0.3 \mathrm{mmol})$ is added. At specified time points in the reaction, 0.5 $\mathrm{mL}$ aliquots are removed under positive hydrogen pressure. The crude reaction aliquots are analyzed using gas chromatography.

\section{Kinetics Experiments on Crabtree's Catalyst}

A $100 \mathrm{~mL}$ flame dried three-neck flask equipped with a flushing adapter connected to a stoppered gas expansion bag filled with hydrogen was charged with a stock solution of terpinen-4-ol (46.3 $\mathrm{mg}, 0.3 \mathrm{mmol})$ in freshly distilled dichloromethane $(15 \mathrm{~mL})$. After three freeze-pump-thaw cycles, the flask is backfilled with dry nitrogen and the catalyst is added to the thawed solution as a solid. Immediately, hydrogen is introduced to the flask and stirring commenced at room temperature. At specified time points in the reaction, $0.5 \mathrm{~mL}$ aliquots were removed from the flask and injected into $0.5 \mathrm{~mL} \mathrm{Et}_{2} \mathrm{O}$ under positive hydrogen pressure. The aliquots were immediately analyzed using gas chromatography with no further work up. 


\section{Reinjection Experiments on Crabtree's Catalyst}

The standard solution and catalytic reaction set up are identical to the kinetics experiment. After $0.5 \mathrm{~h}$ when the reaction has reached full conversion, the solution is stirred under hydrogen for an additional $1.5 \mathrm{~h}$ before a second equivalent of terpinen-4-ol $(46.3 \mathrm{mg}, 0.3 \mathrm{mmol})$ is injected into the solution as a neat liquid. The reaction is stirred under hydrogen for an additional $11 \mathrm{~h}$, and reaction progress is monitored via gas chromatography.

\section{Crude Reaction Analysis using Gas Chromatography}

Reaction conversion and product diastereomeric ratio were obtained using gas chromatography (GC). Catalytic conversions were obtained based on consumption of the starting material peak relative to a decane or dodecane internal standard. The directed and undirected diastereomers for terpinen-4-ol and terpinen-4-ol methyl ether were identified through comparison to a standard sample prepared using Crabtree's catalyst, which shows 99:1 dr for the directed product on both substrates based on literature reports (Figure S12). ${ }^{8}$ The diastereomeric products of the limonene hydrogenation, cis- and trans- $p$-menthane, were also identified by GC through comparison to literature $\mathrm{Pd} / \mathrm{C}$ catalysts. $^{3}$

\section{Crude Reaction Analysis using NMR}

For substrates where GC analysis was insufficient to identify product diastereomers, NMR analysis was also performed. Product diastereomers were identified through comparison to literature compounds for the following substrates: 3 -methyl-2-cyclohexenol, ${ }^{8}$ cis- and trans-carveol, ${ }^{9}$ cisand trans-piperitol. ${ }^{8,10}$ Integrations of the hydroxyl $\alpha$-protons were utilized to determine diastereomeric ratios. 


\section{Physical Characterization Methods}

Energy-dispersive X-ray Fluorescence (XRF) was performed on a Malvern Panalytical Epsilon 4 benchtop spectrometer equipped with an Ag anode X-ray tube. Elemental ratios were determined using the Omnian Standardless Analysis Solution. Transmission electron microscopy (TEM) images were acquired with a FEI Tecnai T20 equipped with a $200 \mathrm{kV} \mathrm{LaB}_{6}$ filament. High-angle annular dark-field scanning transmission electron microscopy (HAADF-STEM) and energydispersive spectroscopy (EDS) mapping were collected on a FEI Talos F200X S/TEM with a XFEG field-emission source of $200 \mathrm{kV}$ and a super X-EDS system. Powder X-ray diffraction (XRD) was performed on a Panalytical Empyrean Powder X-ray diffractometer with a $\mathrm{Cu} \mathrm{K} \alpha$ source (1.54 $\AA$ ) and a high speed PIXcel 3D Medipix detector. Continuous scans were collected between $2 \theta=$ $30-90^{\circ}$ with a step size of $0.013^{\circ}$ and a time per step of $12.75 \mathrm{~s}$ using a reflection/transmission spinner in Bragg-Brentano mode. CO chemisorption measurements were obtained using a Micromeritics ASAP 2020. Measurements were done at $35{ }^{\circ} \mathrm{C}$ from 30-500 torr, and CO adsorption on Pd was determined from the difference between two repeat isotherms. A binding stoichiometry of 1:2 CO:Pd was assumed in order to calculate dispersion. ${ }^{11}$

Gas chromatography was obtained on an Agilent 7890A GC using an HP-5 column (5\% phenyl and $95 \%$ dimethylpolysiloxane functionalization) and products were quantified using a flame ionization detector. ${ }^{1} \mathrm{H}$ and ${ }^{13} \mathrm{C}$ NMR spectra were recorded on a Bruker DRX500 Spectrometer equipped with a $5 \mathrm{~mm}$ BBFO Z-gradient ATM probe operating at $499.89 \mathrm{MHz}$ and $125.69 \mathrm{MHz}$, respectively or a Varian $300 \mathrm{MHz}$ Mercury or INOVA spectrometer equipped with $5 \mathrm{~mm} 4$ nucleus/BB probe, a Z-axis field gradient module, and a sample temperature control unit. Chemical shifts are reported relative to $\mathrm{Si}\left(\mathrm{CH}_{3}\right)_{4}$ using residual ${ }^{1} \mathrm{H}$ and ${ }^{13} \mathrm{C}$ chemical shifts of the solvent as a secondary standard.

\section{X-ray Absorption Spectroscopy (XAS)}

XAS experiments were carried out at the 10-ID-C and 10-BM-B beamlines at the Advanced Photon Source (APS), Argonne National Laboratory at the Pd K-edge (24.350 keV), and Cu Kedge $(8.979 \mathrm{keV})$ in transmission mode. Silica or alumina supported nanoparticle samples were ground to a fine powder, pressed to form a self-supported pellet and sealed in a gas-tight sample holder. During each measurement, the appropriate metal foil was scanned simultaneously through a third ion chamber for internal energy calibration: Pd foil $(24.350 \mathrm{keV})$ and $\mathrm{Cu}$ foil $(8.979 \mathrm{keV})$.

EXAFS fitting was performed using the Artemis software, part of the Demeter software package. ${ }^{12}$ $\mathrm{Pd}$ and $\mathrm{Cu}$ foils were first fit to their known crystallographic structures in order to determine an appropriate amplitude reduction factor $\left(\mathrm{S}_{0}{ }^{2}\right)$ for each elemental edge. Spectra were fit to several potential crystallographic structures: $\mathrm{Pd}, \mathrm{Cu}, \mathrm{Pd}_{3} \mathrm{Cu}, \mathrm{Pd}_{1} \mathrm{Cu}_{1}, \mathrm{PdO}, \mathrm{CuO}$, and $\mathrm{Cu}_{2} \mathrm{O}$. EXAFS coordination parameters were obtained by a least squares fit in $\mathrm{R}$-space of the $\mathrm{k}^{2}$-weighted Fourier transform data from 3-11 $\AA^{-1}$ at the Pd K-edge and 3-9 $\AA^{-1}$ at the Cu K-edge. The following parameters were refined during the fit: average coordination number $(\mathrm{CN})$, alignment offset energy $(\Delta \mathrm{E})$, and path length adjustment $(\Delta \mathrm{R})$. 


\section{Supplementary Data and Figures}
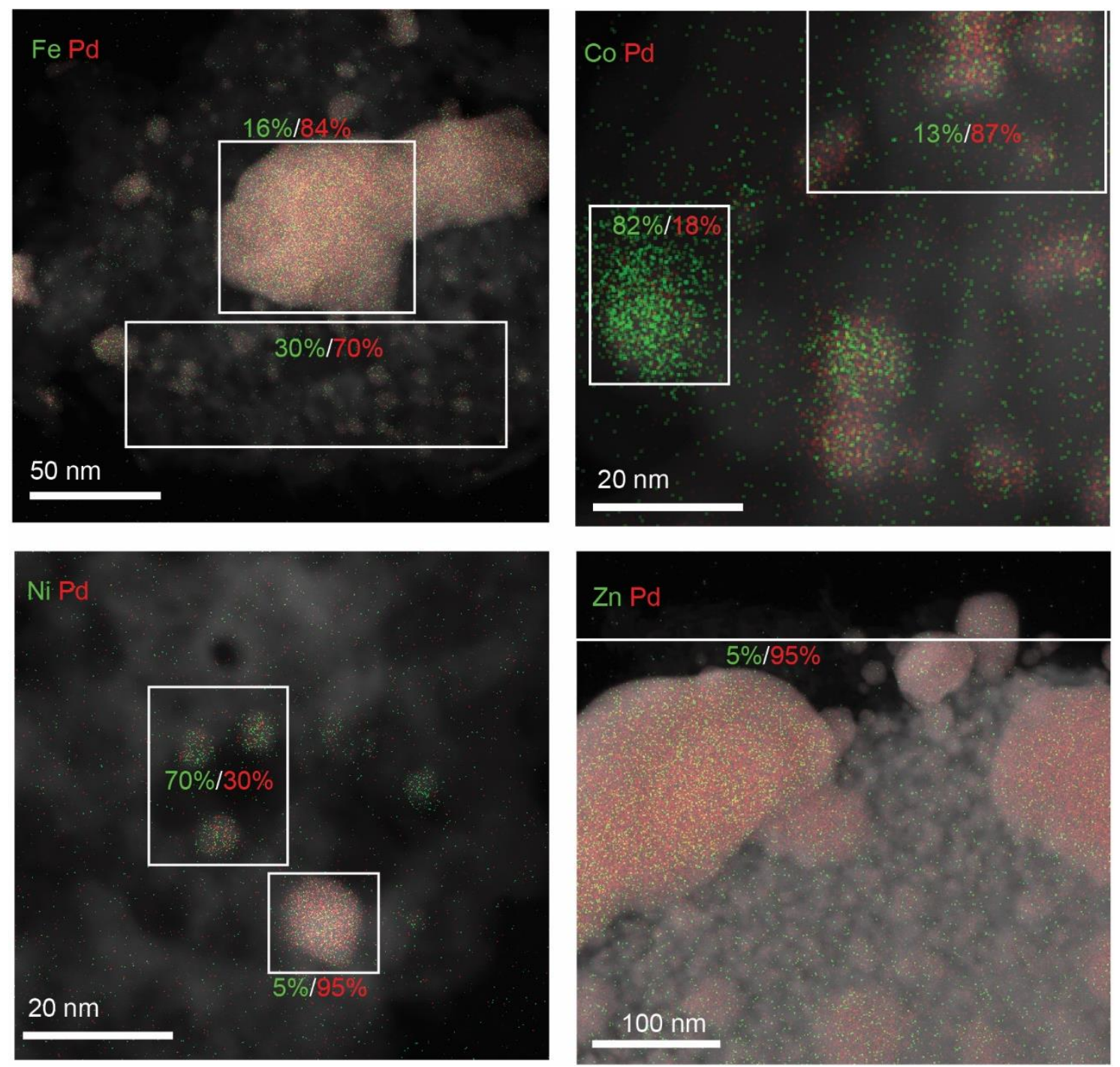

Figure S1. Overlay of HAADF-STEM images and EDS maps for $\mathrm{Pd}_{3} \mathrm{M} / \mathrm{Al}_{2} \mathrm{O}_{3}(\mathrm{M}=\mathrm{Fe}, \mathrm{Co}, \mathrm{Ni}$, $\mathrm{Zn}$ ) samples synthesized through co-impregnation and $800{ }^{\circ} \mathrm{C}_{2}$ reduction. EDS elemental ratios were quantified in each of the boxed regions on the image and the atomic percentages for $\mathrm{M}$ and Pd are provided. 
a)

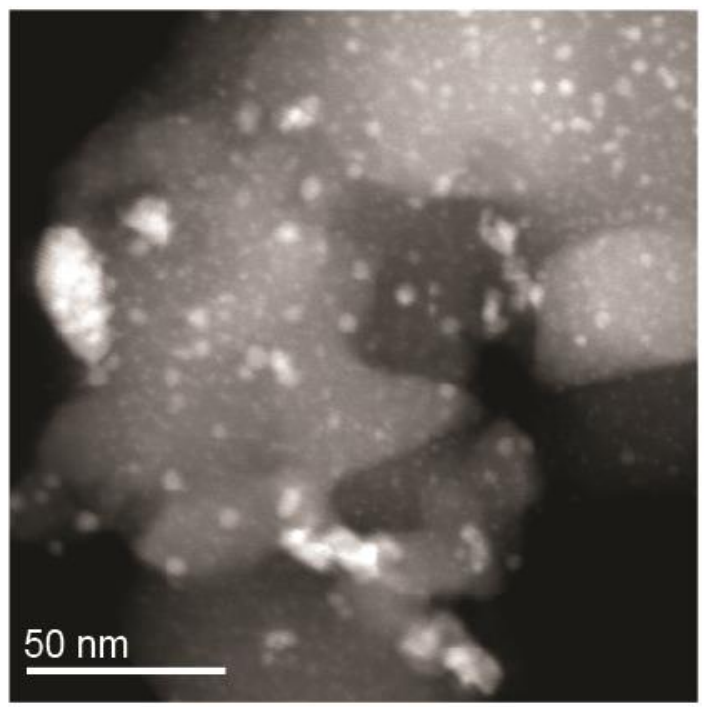

c)

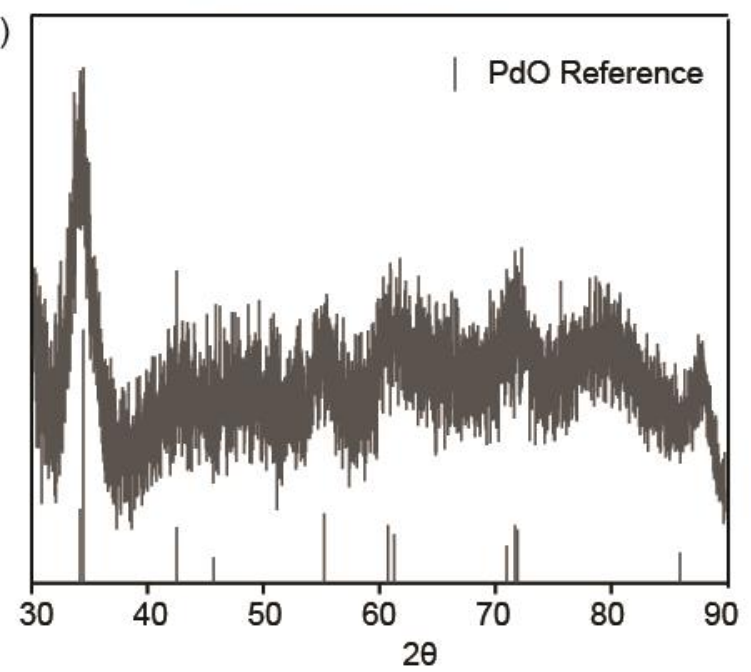

b) $\mathrm{Pd} \mathrm{Cu}$
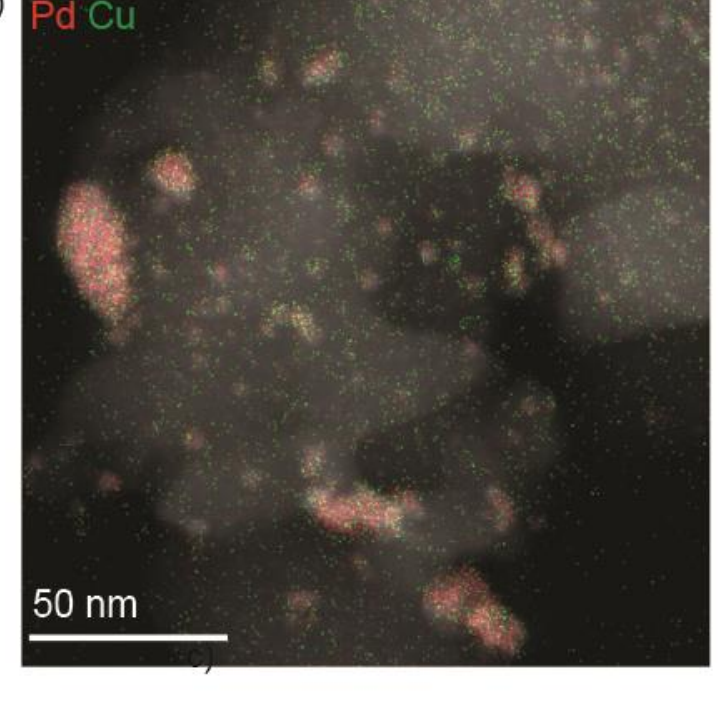

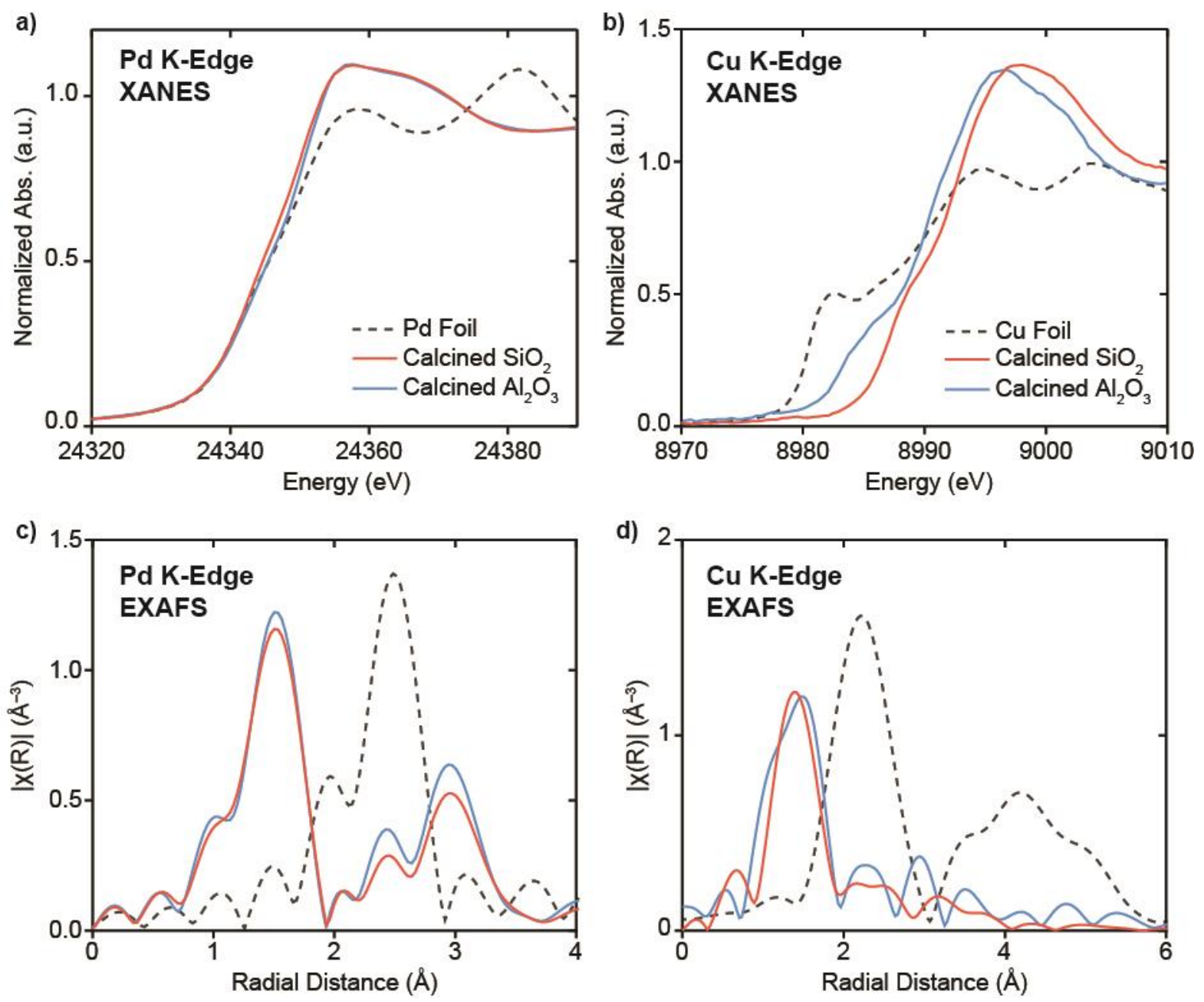

Figure S3. X-ray absorption data on the Calcined $\mathrm{Pd}_{3} \mathrm{Cu}$ samples supported on $\mathrm{SiO}_{2}$ and $\mathrm{Al}_{2} \mathrm{O}_{3}$. (a) Pd K-edge XANES, (b) Cu K-edge XANES, (c) Pd K-edge EXAFS, and (d) Cu K-edge EXAFS. 

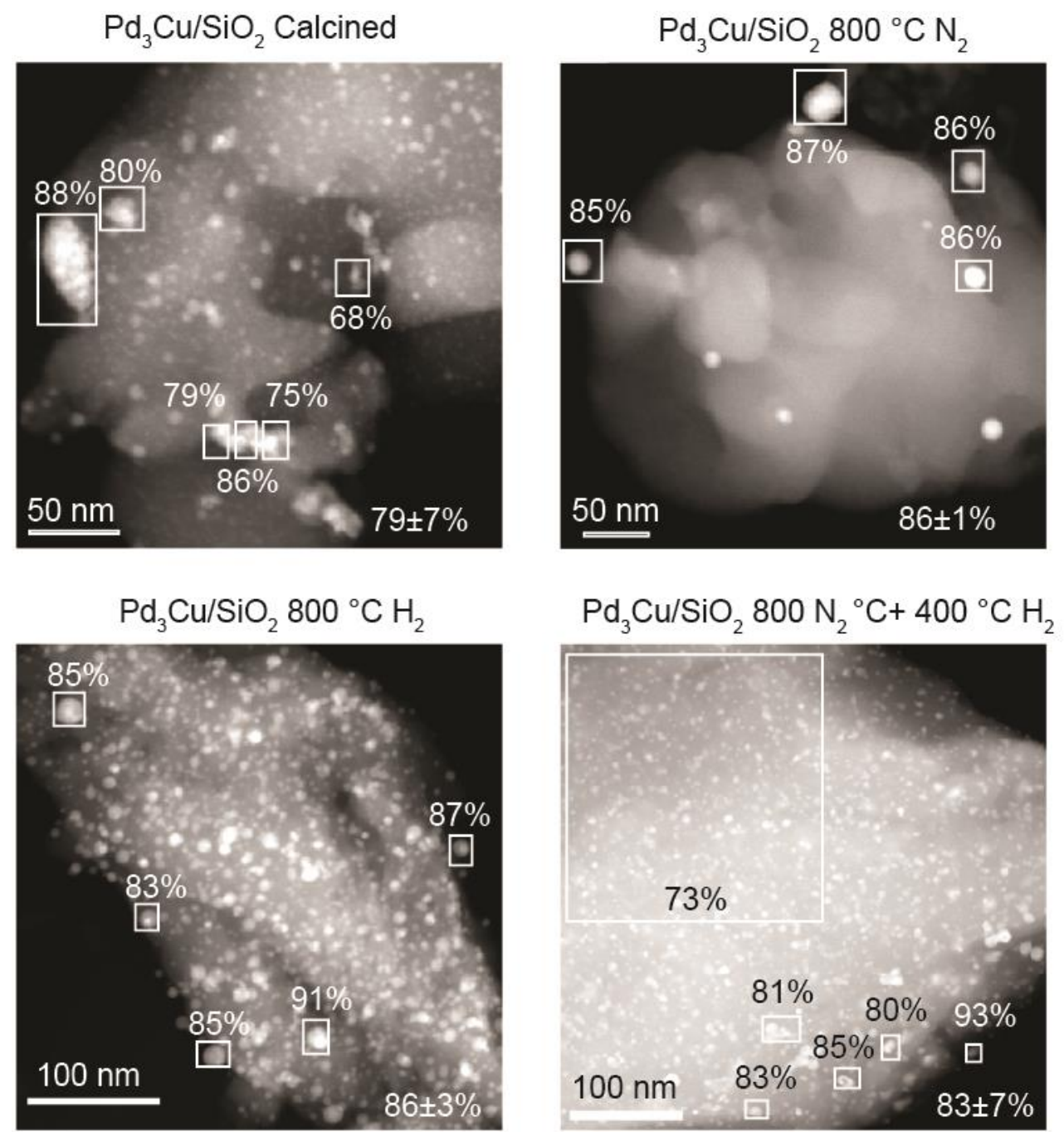

Figure S4. Additional STEM images for thermally-treated $\mathrm{Pd}_{3} \mathrm{Cu} / \mathrm{SiO}_{2}$ samples. EDS spectra were collected in each of the boxed regions on the image and the \% $\mathrm{Pd}$ is provided. 
a)

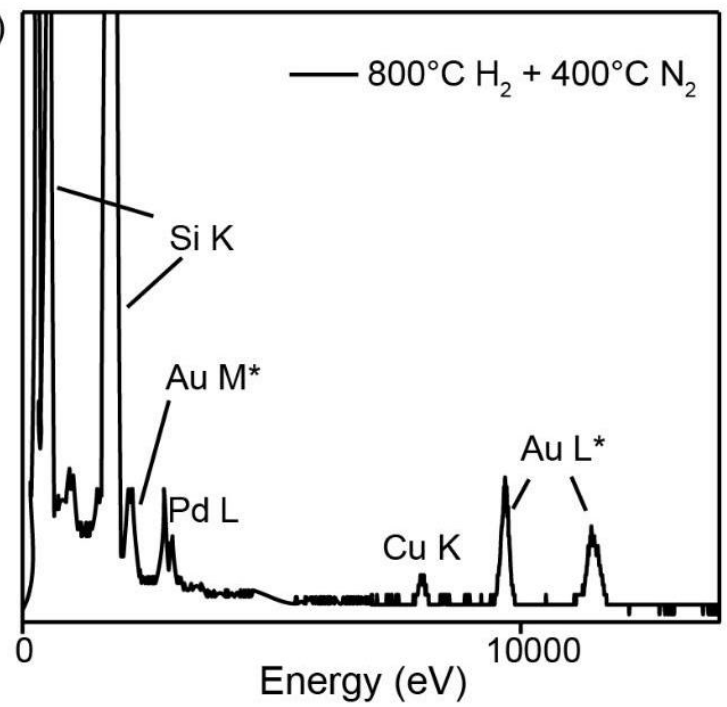

b)

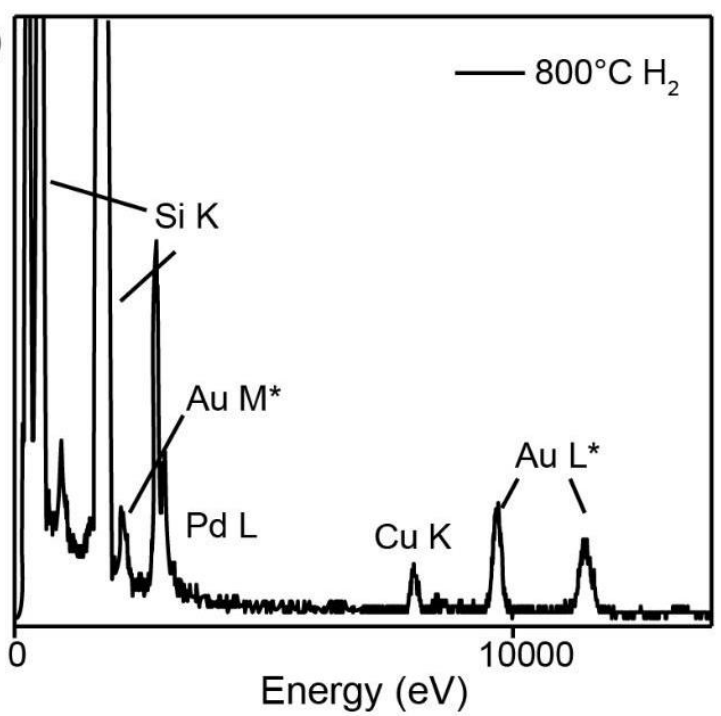

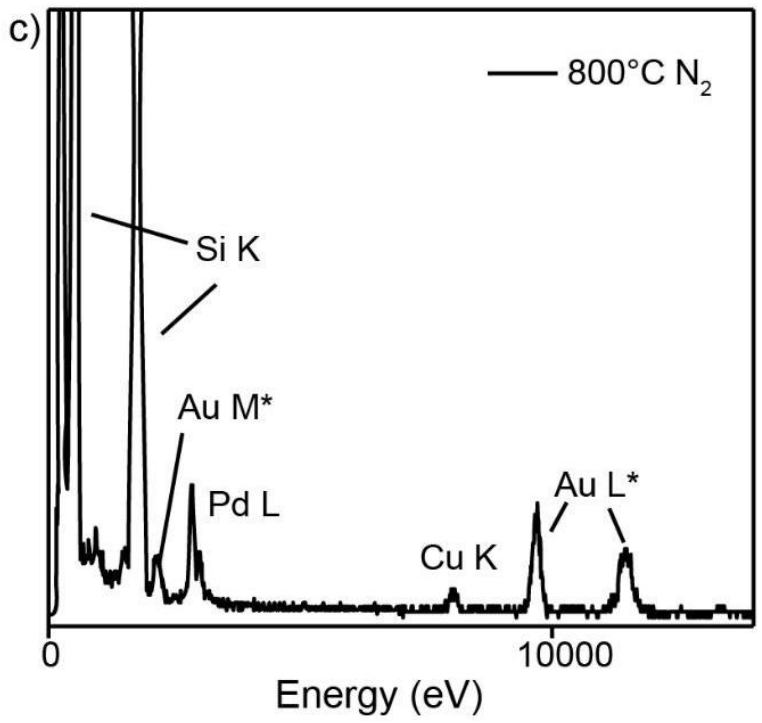

*From TEM grid background

Figure S5. Representative EDS spectra for thermally treated $\mathrm{Pd}_{3} \mathrm{Cu} / \mathrm{SiO}_{2}$ samples 

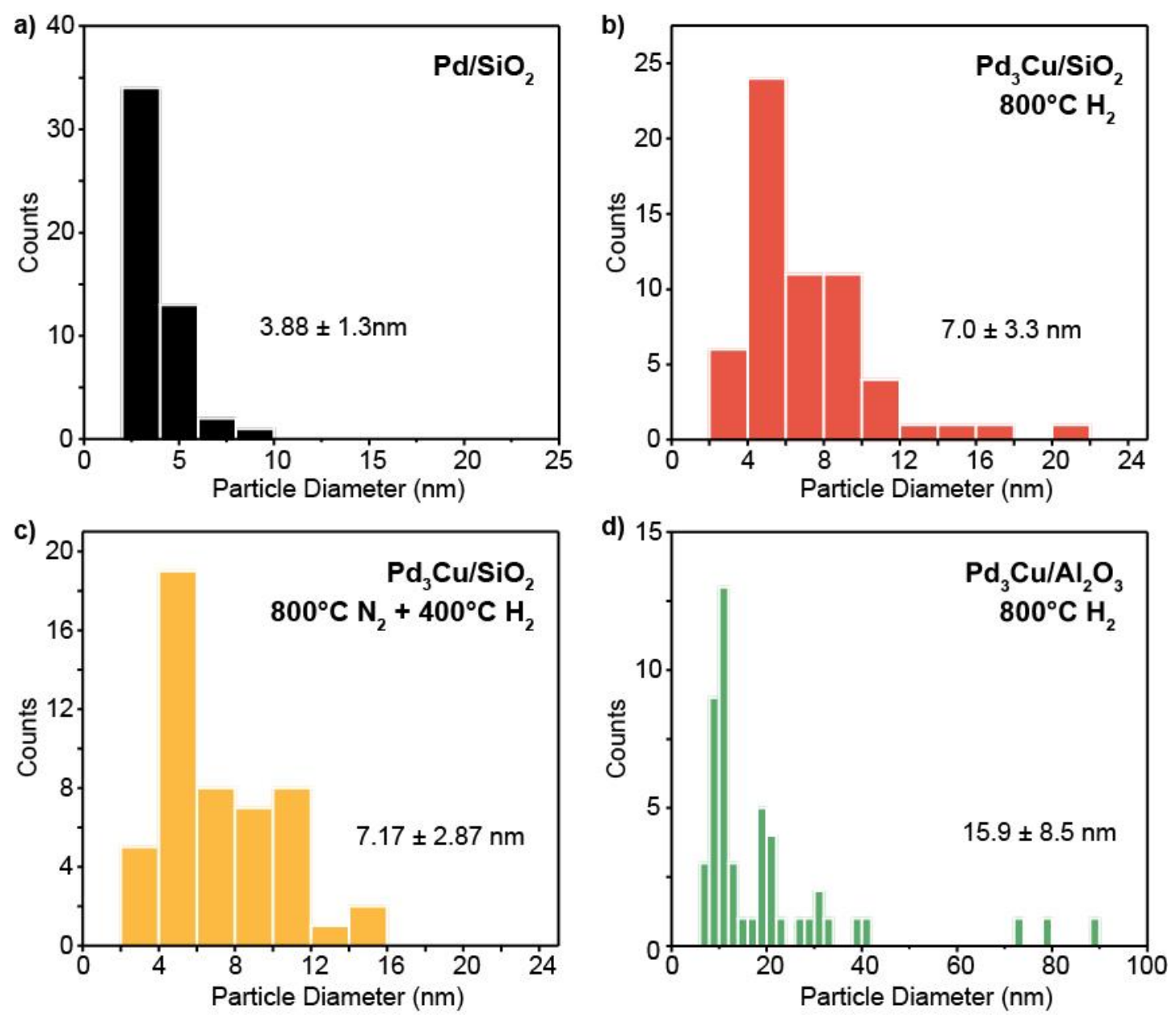

Figure S6. Histogram of nanoparticle sizes for $\mathrm{Pd}$ and thermally-treated $\mathrm{Pd}_{3} \mathrm{Cu}$ samples. 
Table S1. Average elemental analysis obtained using EDS and XRF for thermally-treated $\mathrm{Pd}_{3} \mathrm{Cu}$ samples.

\begin{tabular}{|c|c|c|c|c|}
\hline Catalyst & \multicolumn{2}{|c|}{ EDS* } & \multicolumn{2}{c|}{ XRF $\uparrow$} \\
\hline & $\mathrm{Pd}($ at.\%) & $\mathrm{Cu}$ (at.\%) & $\mathrm{Pd}$ (at.\%) & $\mathrm{Cu}$ (at.\%) \\
\hline $\mathrm{Pd}_{3} \mathrm{Cu} / \mathrm{SiO}_{2} 800^{\circ} \mathrm{C} \mathrm{H} \mathrm{H}_{2}$ & 86 & 14 & 70 & 30 \\
\hline $\mathrm{Pd}_{3} \mathrm{Cu} / \mathrm{SiO}_{2} 800^{\circ} \mathrm{C} \mathrm{N}_{2}-400^{\circ} \mathrm{C} \mathrm{H}_{2}$ & 83 & 17 & 70 & 30 \\
\hline $\mathrm{Pd}_{3} \mathrm{Cu} / \mathrm{SiO}_{2} 800^{\circ} \mathrm{C} \mathrm{N}_{2}$ & 86 & 14 & 72 & 28 \\
\hline $\mathrm{Pd}_{3} \mathrm{Cu} / \mathrm{Al}_{2} \mathrm{O}_{3} 800^{\circ} \mathrm{C} \mathrm{H}_{2}$ & 66 & 34 & 73 & 27 \\
\hline $\mathrm{Calcined} \mathrm{Pd}_{3} \mathrm{Cu} / \mathrm{SiO}_{2}$ & 79 & 21 & 70 & 30 \\
\hline
\end{tabular}

*EDS spectra are taken in areas that are dominated by metallic nanoparticles, which results in a higher Pd content (See Figure S4).

$\dagger$ Significant $\mathrm{CuO}_{\mathrm{x}}$ species remain unincorporated on the support, as evidenced by the much larger $\mathrm{Cu}$ at.\% observed by XRF. 
Table S2. XRD peak positions and calculated lattice parameters for thermally-treated $\mathrm{Pd}_{3} \mathrm{Cu}$ samples.

\begin{tabular}{|c|c|c|c|c|}
\hline Sample & $\begin{array}{l}\text { Miller Indices } \\
\text { (hkl) }\end{array}$ & $\begin{array}{c}\text { Peak Position } \\
\text { (20) }\end{array}$ & d-spacing $(\AA)$ & $\begin{array}{c}\text { Lattice } \\
\text { Parameter }(\AA)\end{array}$ \\
\hline \multirow{4}{*}{$\begin{array}{c}\mathrm{Pd}_{3} \mathrm{Cu} / \mathrm{SiO}_{2} \\
800^{\circ} \mathrm{C} \mathrm{H}_{2}\end{array}$} & (111) & 40.82 & 2.209 & \multirow{4}{*}{$3.833 \pm 0.005$} \\
\hline & (200) & 47.43 & 1.915 & \\
\hline & (220) & 69.19 & 1.357 & \\
\hline & (311) & 83.43 & 1.158 & \\
\hline \multirow{4}{*}{$\begin{array}{c}\mathrm{Pd}_{3} \mathrm{Cu} / \mathrm{SiO}_{2} \\
800{ }^{\circ} \mathrm{C} \mathrm{N}_{2}-400{ }^{\circ} \mathrm{C} \mathrm{H}_{2}\end{array}$} & (111) & 40.59 & 2.221 & \multirow{4}{*}{$3.854 \pm 0.006$} \\
\hline & (200) & 47.18 & 1.925 & \\
\hline & (220) & $\begin{array}{l}68.79 \\
\end{array}$ & 1.364 & \\
\hline & (311) & 82.84 & 1.164 & \\
\hline \multirow{4}{*}{$\begin{array}{c}\mathrm{Pd}_{3} \mathrm{Cu} / \mathrm{SiO}_{2} \\
800{ }^{\circ} \mathrm{C} \mathrm{N}_{2}\end{array}$} & (111) & 40.57 & 2.222 & \multirow{4}{*}{$3.855 \pm 0.005$} \\
\hline & (200) & 47.17 & 1.925 & \\
\hline & (220) & 68.79 & 1.364 & \\
\hline & (311) & 82.83 & 1.165 & \\
\hline \multirow{4}{*}{$\begin{array}{c}\mathrm{Pd}_{3} \mathrm{Cu} / \mathrm{Al}_{2} \mathrm{O}_{3} \\
800^{\circ} \mathrm{C} \mathrm{H}_{2}\end{array}$} & (111) & 40.76 & 2.212 & \multirow{4}{*}{$3.837 \pm 0.003$} \\
\hline & (200) & 47.37 & 1.918 & \\
\hline & (220) & 69.15 & 1.357 & \\
\hline & (311) & 83.42 & 1.158 & \\
\hline
\end{tabular}



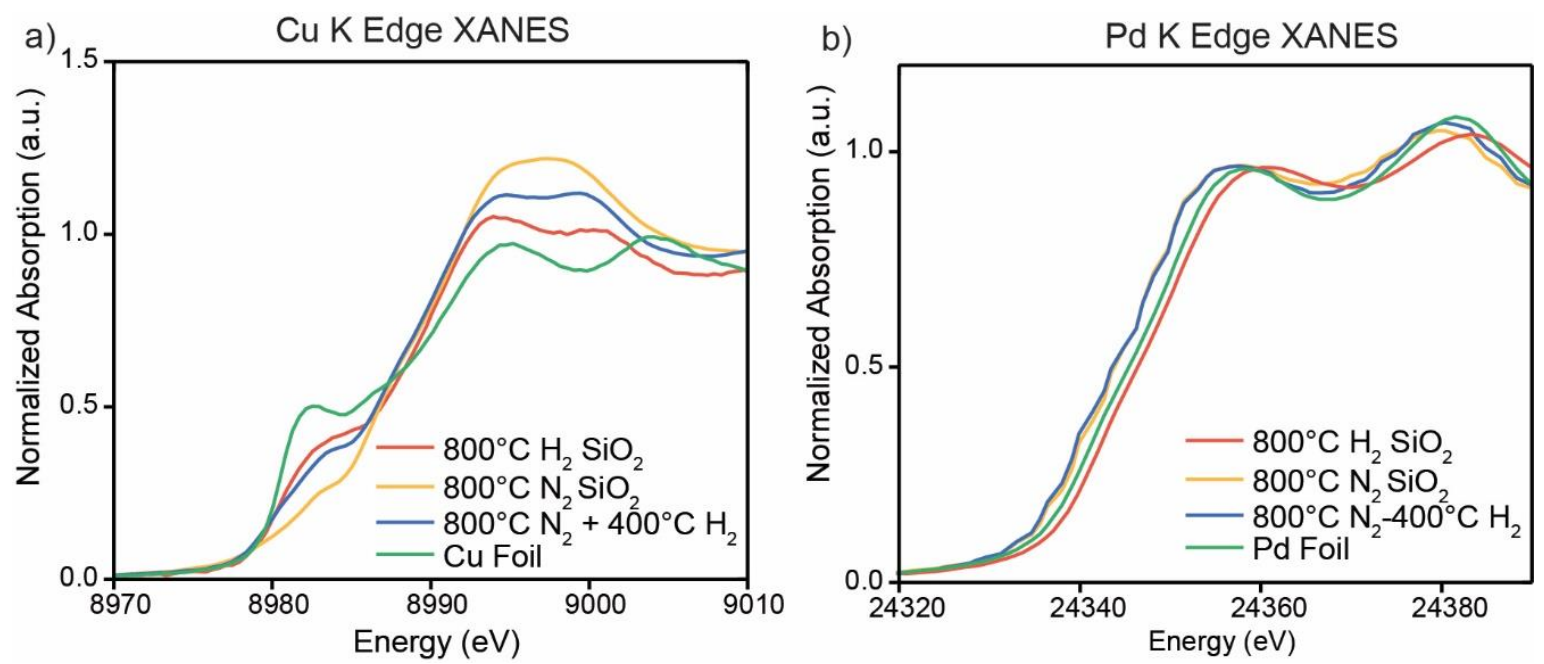

Figure S7. XANES spectra for thermally treated $\mathrm{Pd}_{3} \mathrm{Cu} / \mathrm{SiO}_{2}$ samples at the (a) $\mathrm{Cu} \mathrm{K}$-edge and (b) Pd K-edge.

Table S3. $\mathrm{Pd}$ and $\mathrm{Cu}$ K-edge XAS fitting parameters for reference foils and additional $\mathrm{Pd}_{3} \mathrm{Cu}$ samples.

\begin{tabular}{|c|c|c|c|c|c|c|}
\hline Sample & Edge & $\begin{array}{c}\text { Scattering } \\
\text { Pair }\end{array}$ & $\mathrm{CN}$ & $\mathrm{R}(\AA)$ & $\sigma^{2}\left(\AA^{2}\right)^{\mathrm{a}}$ & $\mathrm{E}_{0}(\mathrm{eV})$ \\
\hline Pd Foil (Ref) & $\mathrm{Pd}$ & $\mathrm{Pd}-\mathrm{Pd}$ & 12 & 2.750 & 0.005 & -3.3 \\
\hline Cu Foil (Ref) & $\mathrm{Cu}$ & $\mathrm{Cu}-\mathrm{Cu}$ & 12 & 2.556 & 0.009 & 6.2 \\
\hline \multirow{4}{*}{$\begin{array}{c}\mathrm{Pd}_{3} \mathrm{Cu} / \mathrm{Al}_{2} \mathrm{O}_{3} \\
800^{\circ} \mathrm{C} \mathrm{H}_{2}\end{array}$} & \multirow{2}{*}{$\mathrm{Pd}$} & $\mathrm{Pd}-\mathrm{Pd}$ & $8.1 \pm 0.7$ & \multirow{2}{*}{$2.754 \pm 0.004$} & \multirow{2}{*}{0.005} & \multirow{2}{*}{$-6.3 \pm 0.6$} \\
\hline & & $\mathrm{Pd}-\mathrm{Cu}$ & $1.3 \pm 0.7$ & & & \\
\hline & \multirow{2}{*}{$\mathrm{Cu}$} & $\mathrm{Cu}-\mathrm{O}$ & $1.4 \pm 0.3$ & $1.936 \pm 0.020$ & \multirow{2}{*}{0.009} & \multirow{2}{*}{$-2.2 \pm 0.5$} \\
\hline & & $\mathrm{Cu}-\mathrm{Pd}$ & $5.1 \pm 0.2$ & $2.724 \pm 0.005$ & & \\
\hline \multirow{2}{*}{$\begin{array}{c}\text { Calcined } \\
\mathrm{Pd}_{3} \mathrm{Cu} / \mathrm{Al}_{2} \mathrm{O}_{3}\end{array}$} & $\mathrm{Pd}$ & $\mathrm{Pd}-\mathrm{O}$ & $3.9 \pm 0.1$ & $2.014 \pm 0.003$ & 0.001 & $-0.6 \pm 0.4$ \\
\hline & $\mathrm{Cu}$ & $\mathrm{Cu}-\mathrm{O}$ & $4.0 \pm 0.3$ & $1.929 \pm 0.007$ & 0.005 & $1.4 \pm 1.0$ \\
\hline \multirow{2}{*}{$\begin{array}{c}\text { Calcined } \\
\mathrm{Pd}_{3} \mathrm{Cu} / \mathrm{SiO}_{2}\end{array}$} & $\mathrm{Pd}$ & $\mathrm{Pd}-\mathrm{O}$ & $3.9 \pm 0.1$ & $2.020 \pm 0.002$ & 0.001 & $-1.7 \pm 0.3$ \\
\hline & $\mathrm{Cu}$ & $\mathrm{Cu}-\mathrm{O}$ & $3.4 \pm 0.3$ & $1.910 \pm 0.007$ & 0.001 & $-5.0 \pm 1.2$ \\
\hline
\end{tabular}

${ }^{\mathrm{a}} \sigma^{2}$ values are determined based on metal foil references and fixed during the EXAFS fitting. 

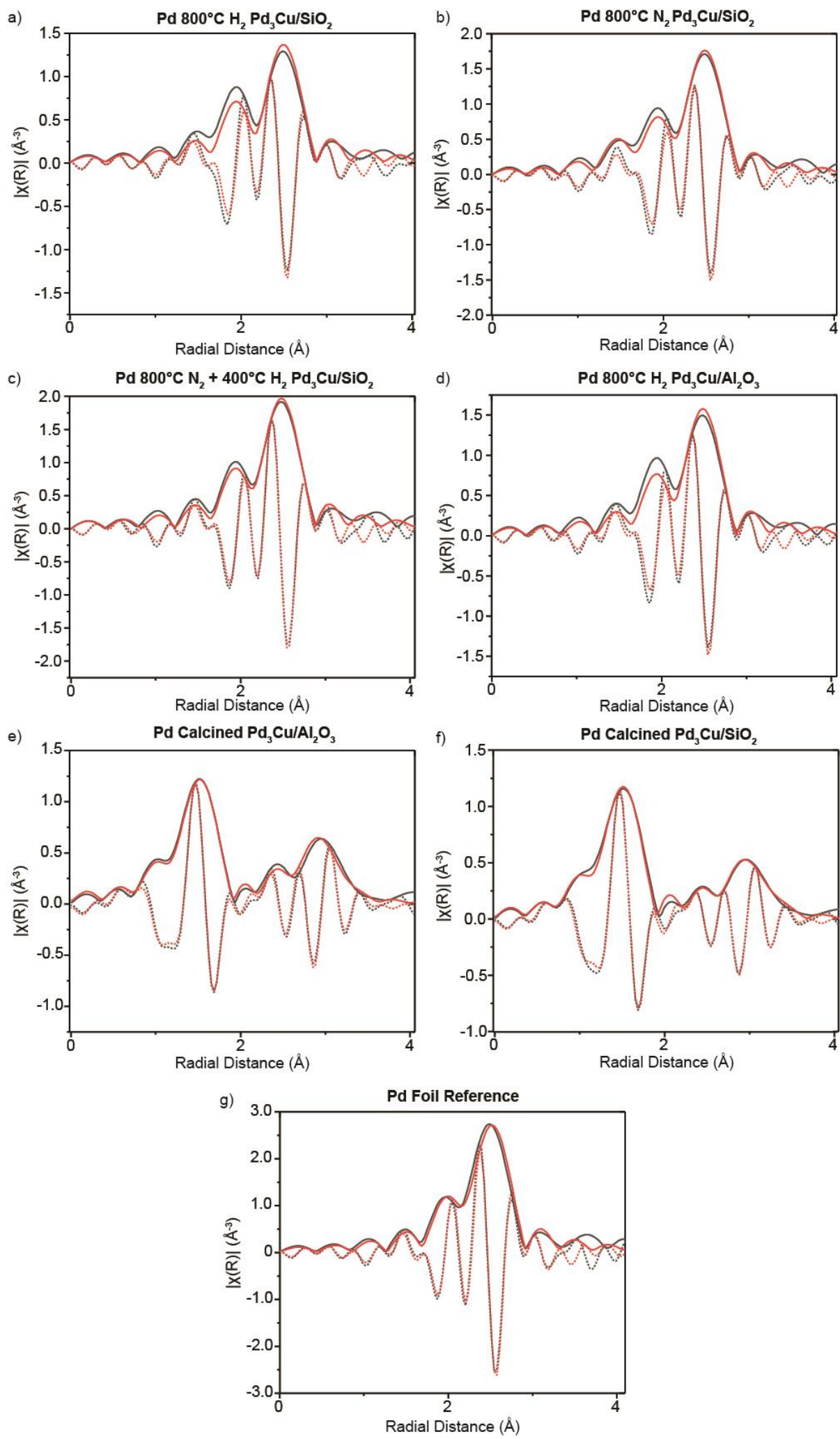

Figure S8. Pd K-edge EXAFS fitting results for all $\mathrm{Pd}_{3} \mathrm{Cu}$ and reference samples. The black solid line is the FT magnitude, the red solid line is the fit to the FT magnitude, the black dotted line is the FT real part, and the red dotted line is the fit to the FT real part. 

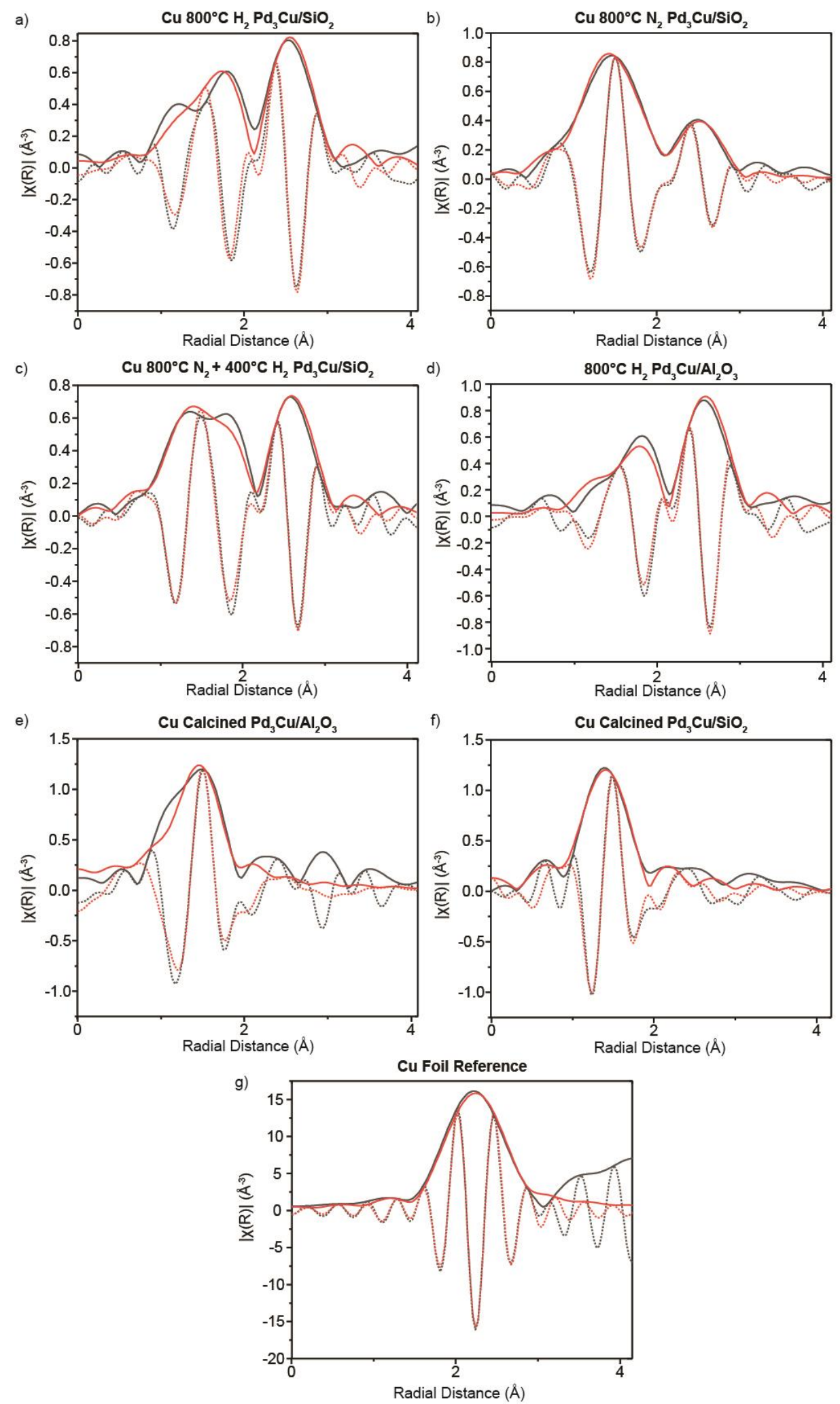

Figure S9. $\mathrm{Cu} \mathrm{K}$-edge EXAFS fitting results for all $\mathrm{Pd}_{3} \mathrm{Cu}$ and reference samples. The black solid line is the FT magnitude, the red solid line is the fit to the FT magnitude, the black dotted line is the FT real part, and the red dotted line is the fit to the FT real part. 

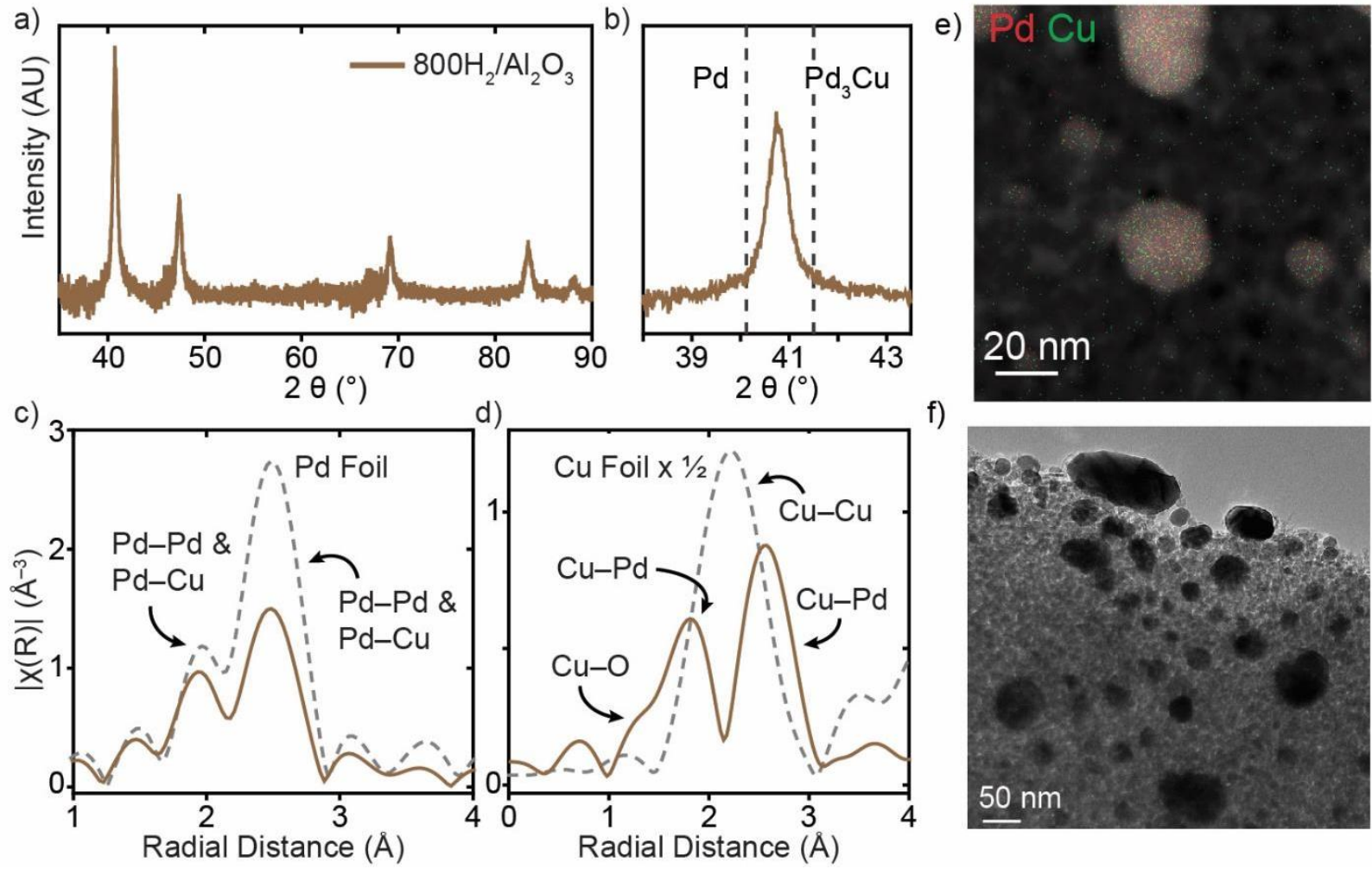

f)

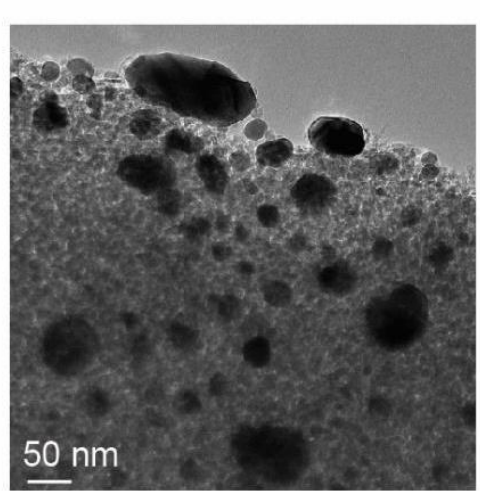

Figure S10. Characterization data on the $800 \mathrm{H}_{2} \mathrm{Pd}_{3} \mathrm{Cu} / \mathrm{Al}_{2} \mathrm{O}_{3}$ sample. (a) Powder XRD pattern, (b) close-up of XRD (111) peak, (c) Pd K-edge EXAFS, (d) Cu K-edge EXAFS. (e) STEM-EDS map, and (f) TEM image. 

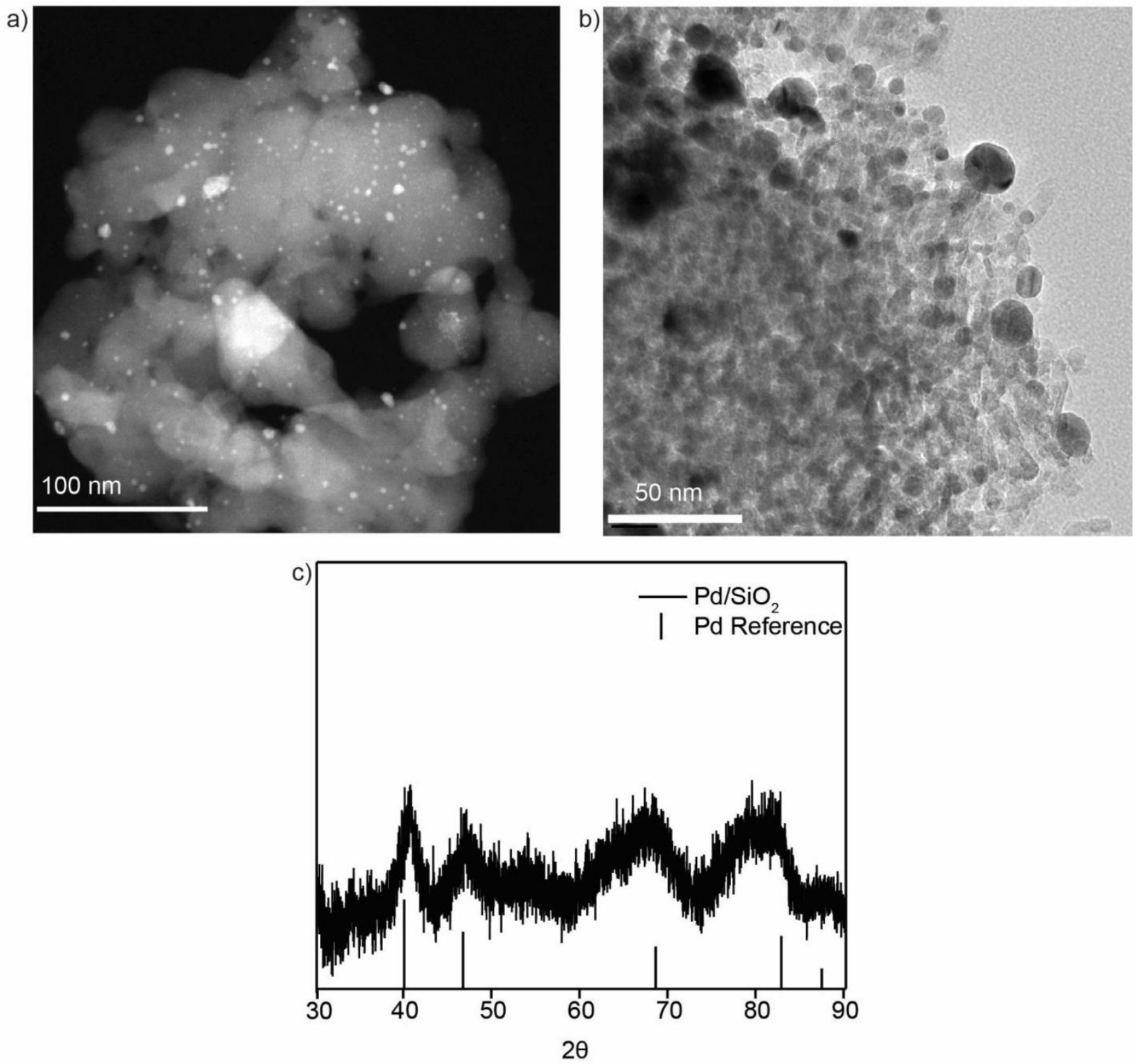

Figure S11. (a) HAADF-STEM image of $\mathrm{Pd} / \mathrm{SiO}_{2}$, (b) TEM image of $\mathrm{Pd} / \mathrm{Al}_{2} \mathrm{O}_{3}$, and (c) powder XRD pattern for $\mathrm{Pd} / \mathrm{SiO}_{2}$. 
Table S4. Catalytic hydrogenation data for triplicate runs to high conversion for all substrates and catalysts described in Table 3 of the main text.<smiles>CC1=CC[C@](O)(C(C)C)CC1</smiles>

\begin{tabular}{|c|c|c|c|c|}
\hline & Time & Conversion & $\mathrm{dr}(\mathrm{P} 1: \mathrm{P} 2)$ & Average dr \\
\hline \multirow{3}{*}{$\begin{array}{c}\mathrm{Pd}_{3} \mathrm{Cu} / \mathrm{SiO}_{2} \\
800{ }^{\circ} \mathrm{C} \mathrm{N}_{2}+400{ }^{\circ} \mathrm{C} \mathrm{H}_{2}\end{array}$} & $20 \mathrm{~h}$ & 95 & $17: 1$ & \multirow{3}{*}{$16 \pm 1: 1$} \\
\hline & $20 \mathrm{~h}$ & $>99$ & $15: 1$ & \\
\hline & $20 \mathrm{~h}$ & $>99$ & $16: 1$ & \\
\hline \multirow{3}{*}{$\begin{array}{c}\mathrm{Pd}_{3} \mathrm{Cu} / \mathrm{SiO}_{2} \\
800{ }^{\circ} \mathrm{C} \mathrm{H}_{2}\end{array}$} & $20 \mathrm{~h}$ & 95 & $2.7: 1$ & \multirow{3}{*}{$2.8 \pm 0.1: 1$} \\
\hline & $20 \mathrm{~h}$ & 91 & $2.8: 1$ & \\
\hline & $20 \mathrm{~h}$ & 92 & $2.8: 1$ & \\
\hline \multirow{3}{*}{$\mathrm{Pd} / \mathrm{SiO}_{2}$} & $2 \mathrm{~h}$ & $>99$ & $0.39: 1$ & \multirow{3}{*}{$1: 2.7 \pm 0.08$} \\
\hline & $2 \mathrm{~h}$ & $>99$ & $0.37: 1$ & \\
\hline & $2 \mathrm{~h}$ & $>99$ & $0.37: 1$ & \\
\hline
\end{tabular}<smiles>CC1=CC(C(C)C)[C@](C)(C(C)C)CC1</smiles>

\begin{tabular}{|c|c|c|c|c|}
\hline & Time & Conversion & $\mathrm{dr}(\mathrm{P} 1: \mathrm{P} 2)$ & Average dr \\
\hline \multirow{2}{*}{$800{ }^{\circ} \mathrm{Pd} \mathrm{N}_{3} \mathrm{Cu} / \mathrm{SiO}_{2}$} & $20 \mathrm{~h}$ & 99 & 0.44 & \multirow{3}{*}{$1: 2.1 \pm 0.1$} \\
\cline { 2 - 4 } & $20 \mathrm{~h}$ & 98 & 0.49 & \\
\cline { 2 - 4 } & $20 \mathrm{~h}$ & 99 & 0.51 & \multirow{2}{*}{$1: 3.5 \pm 0.1$} \\
\cline { 2 - 4 } $\mathrm{Pd}_{3} \mathrm{Cu} / \mathrm{SiO}_{2}$ & $20 \mathrm{~h}$ & $>99$ & 0.30 & \\
\cline { 2 - 4 } $800{ }^{\circ} \mathrm{C} \mathrm{H}_{2}$ & $20 \mathrm{~h}$ & $>99$ & 0.28 & \\
\cline { 2 - 4 } & $20 \mathrm{~h}$ & $>99$ & 0.28 & \\
\cline { 2 - 4 } & & \multicolumn{2}{|c}{} \\
\hline
\end{tabular}




\begin{tabular}{|l|c|c|c|c|}
\hline \multirow{3}{*}{$\mathrm{Pd} / \mathrm{SiO}_{2}$} & $2 \mathrm{~h}$ & 90 & 0.14 & \multirow{2}{*}{$1: 6.8 \pm 0.09$} \\
\cline { 2 - 4 } & $2 \mathrm{~h}$ & $>99$ & 0.15 & \\
\cline { 2 - 4 } & $2 \mathrm{~h}$ & $>99$ & 0.15 & \\
\hline
\end{tabular}<smiles>CC1=CC[C@H](C(C)C)CC1</smiles>

\begin{tabular}{|c|c|c|c|c|}
\hline & Time & Conversion & $\mathrm{dr}(\mathrm{P} 1: \mathrm{P} 2)$ & Average dr \\
\hline \multirow{3}{*}{$\begin{array}{c}\mathrm{Pd}_{3} \mathrm{Cu} / \mathrm{SiO}_{2} \\
800{ }^{\circ} \mathrm{C} \mathrm{N}_{2}+400{ }^{\circ} \mathrm{C} \mathrm{H}_{2}\end{array}$} & $20 \mathrm{~h}$ & 94 & 0.38 & \multirow{3}{*}{$1: 2.6 \pm 0.01$} \\
\hline & $20 \mathrm{~h}$ & 93 & 0.38 & \\
\hline & $20 \mathrm{~h}$ & 87 & 0.39 & \\
\hline \multirow{3}{*}{$\begin{array}{c}\mathrm{Pd}_{3} \mathrm{Cu} / \mathrm{SiO}_{2} \\
800{ }^{\circ} \mathrm{C} \mathrm{H}_{2}\end{array}$} & $20 \mathrm{~h}$ & 61 & 0.28 & \multirow{3}{*}{$1: 3.4 \pm 0.1$} \\
\hline & $20 \mathrm{~h}$ & 74 & 0.30 & \\
\hline & $20 \mathrm{~h}$ & 70 & 0.29 & \\
\hline \multirow{3}{*}{$\mathrm{Pd} / \mathrm{SiO}_{2}$} & $2 \mathrm{~h}$ & 70 & 0.29 & \multirow{3}{*}{$1: 3.4 \pm 0.01$} \\
\hline & $2 \mathrm{~h}$ & 76 & 0.29 & \\
\hline & $2 \mathrm{~h}$ & 77 & 0.29 & \\
\hline
\end{tabular}



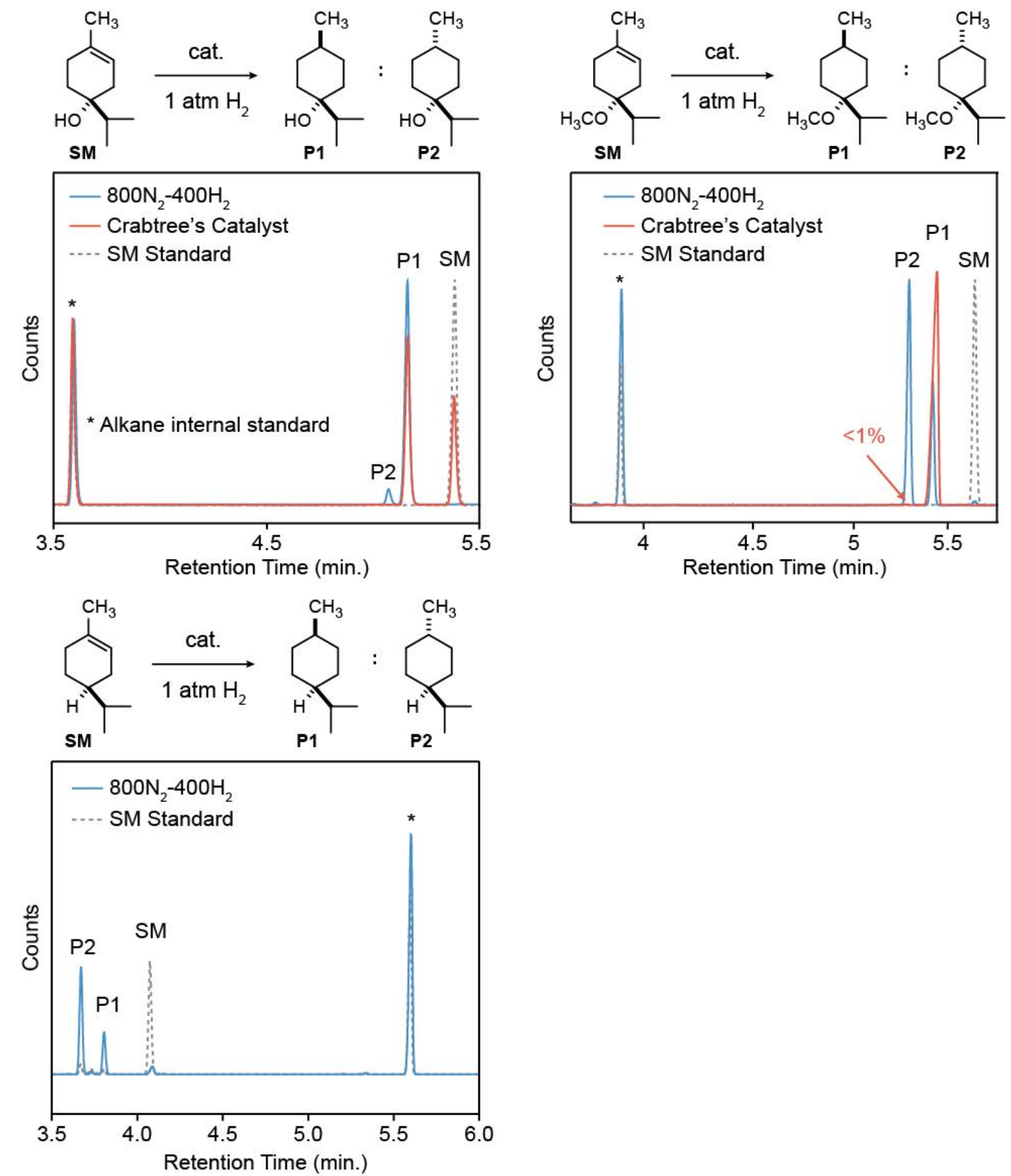

Figure S12. Representative GC traces for the starting material standards and catalytic reactions using both the selective $\mathrm{Pd}_{3} \mathrm{Cu}$ catalyst and $\left[\operatorname{Ir}(\mathrm{cod})\left(\mathrm{PCy}_{3}\right)\left(\mathrm{Py}_{3}\right)\right] \mathrm{PF}_{6}$ (Crabtree's catalyst). 
Table S5. Results for CO chemisorption.

\begin{tabular}{|c|c|c|c|}
\hline Sample & $\begin{array}{c}\text { CO Uptake } \\
(\boldsymbol{\mu m o l} / \mathbf{g})\end{array}$ & Pd wt.\% & Pd Dispersion (\%) \\
\hline $\mathrm{Pd} / \mathrm{SiO}_{2}$ & 31.2 & 2.0 & $34 \%$ \\
\hline $\begin{array}{c}\mathrm{Pd}_{3} \mathrm{Cu} / \mathrm{SiO}_{2} \\
800 \mathrm{H}_{2}\end{array}$ & 3.00 & 1.9 & $3.3 \%$ \\
\hline $\mathrm{Pd}_{3} \mathrm{Cu} / \mathrm{SiO}_{2}$ & 2.53 & 2.2 & $2.5 \%$ \\
$800 \mathrm{H}_{2}-400 \mathrm{~N}_{2}$ & & & \\
\hline
\end{tabular}


Table S6. Reaction conditions and reusability studies for $\mathrm{Pd}_{3} \mathrm{Cu} / \mathrm{SiO}_{2}$ and $\left[\operatorname{Ir}(\operatorname{cod})\left(\mathrm{PCy}_{3}\right)(\mathrm{py})\right] \mathrm{PF}_{6}$.

\begin{tabular}{|c|c|c|c|}
\hline Condition & Time & Conversion & DR (P1:P2) \\
\hline \multicolumn{3}{|c|}{$\mathbf{P d}_{3} \mathbf{C u} / \mathbf{S i O}_{2}$} \\
\hline${ }^{\mathrm{a}}$ Standard Condition (= Wet Solvent) & $20 \mathrm{~h}$ & $86 \pm 6$ & $14 \pm 1: 1$ \\
\hline Dry Solvent & $20 \mathrm{~h}$ & 89 & $11: 1$ \\
\hline Reinjection of Substrate & $20 \mathrm{~h}$ & 77 & $15: 1$ \\
\hline Recycled (Filtered in air) & $20 \mathrm{~h}$ & 31 & $12: 1$ \\
\hline Regenerated (200 ${ }^{\circ} \mathrm{C}_{2}$ ) & $20 \mathrm{~h}$ & 72 & $12: 1$ \\
\hline \multicolumn{2}{|c|}{ Crabtree's Catalyst } \\
\hline${ }^{\mathrm{b}}$ Standard Condition (= Dry Solvent) & $0.5 \mathrm{~h}$ & 99 & $>50: 1$ \\
\hline Wet Solvent & $0.5 \mathrm{~h}$ & 8 & $>50: 1$ \\
\hline Reinjection of Substrate & $2 \mathrm{~h}$ & $<0.1$ & $\mathrm{n} / \mathrm{a}$ \\
\hline
\end{tabular}

${ }^{a}$ Terpinen-4-ol $(0.1 \mathrm{mmol})$ and $\mathrm{Pd}_{3} \mathrm{Cu} @ \mathrm{SiO}_{2}(0.01 \mathrm{mmol} \mathrm{Pd})$ in wet cyclohexane $(5 \mathrm{~mL})$ stirred under a hydrogen atmosphere at $20^{\circ} \mathrm{C}$.

${ }^{b}$ Terpinen-4-ol $(0.3 \mathrm{mmol})$ and $\left[\mathrm{Ir}(\mathrm{cod})\left(\mathrm{PCy}_{3}\right)(\mathrm{py})\right] \mathrm{PF}_{6}(0.0075 \mathrm{mmol})$ in dry $\mathrm{CH}_{2} \mathrm{Cl}_{2}(15 \mathrm{~mL})$ stirred under a hydrogen atmosphere at $20{ }^{\circ} \mathrm{C}$. 

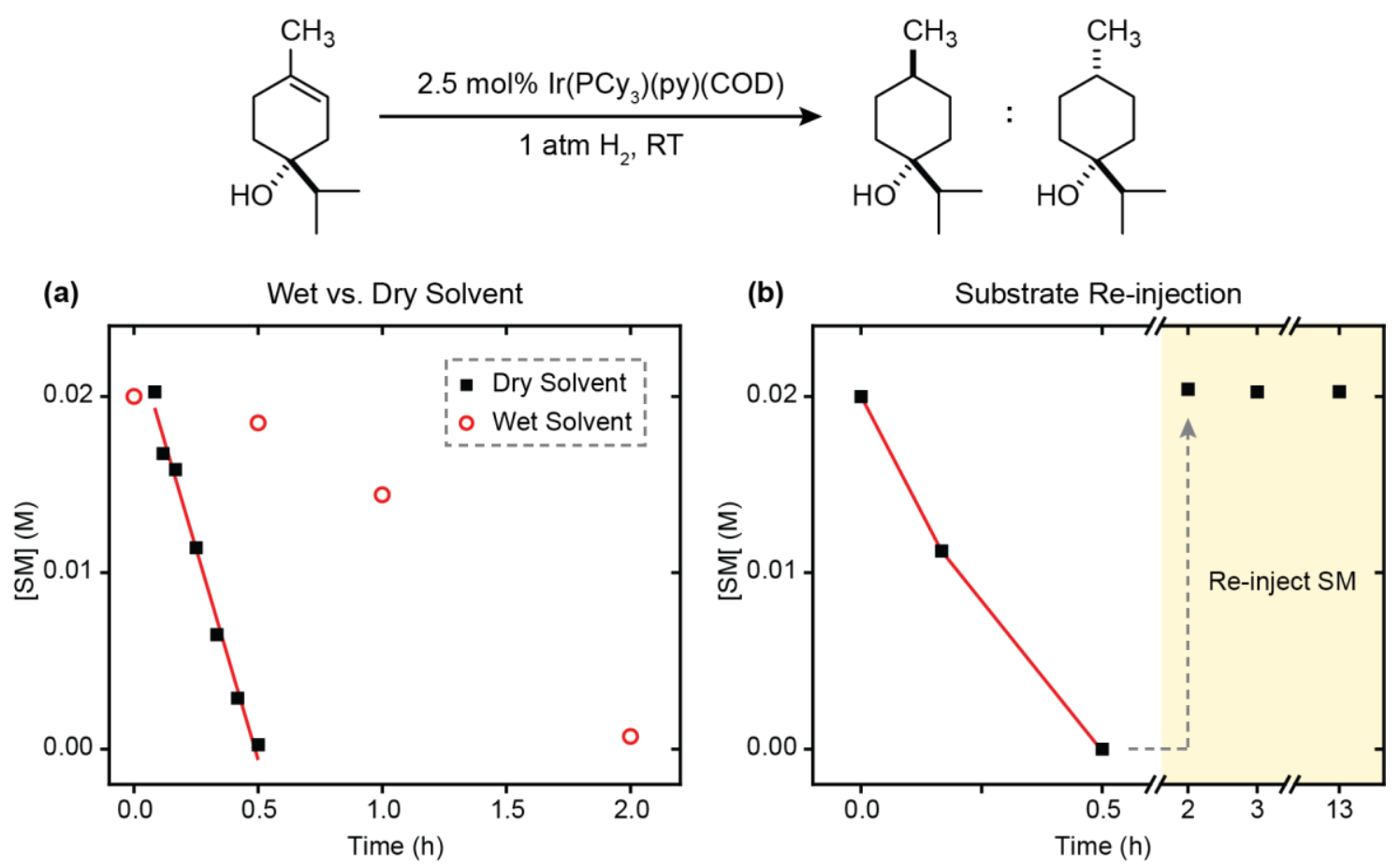

Figure S13. Terpinen-4-ol (SM) hydrogenation over time using Crabtree's catalyst in (a) wet vs. dry $\mathrm{CH}_{2} \mathrm{Cl}_{2}$ and (b) after reinjection of a second aliquot of substrate. 


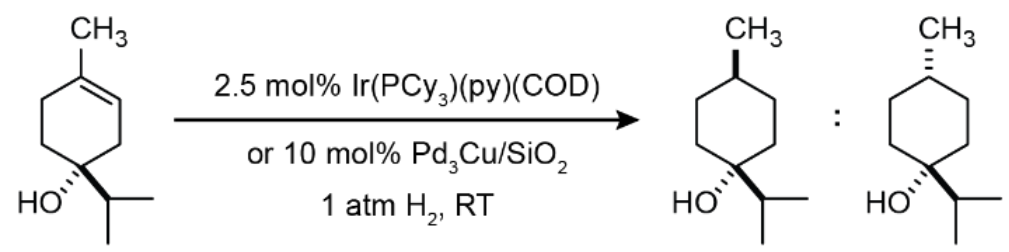

$2.5 \mathrm{~mol} \% \operatorname{Ir}\left(\mathrm{PCy}_{3}\right)(\mathrm{py})(\mathrm{COD})$
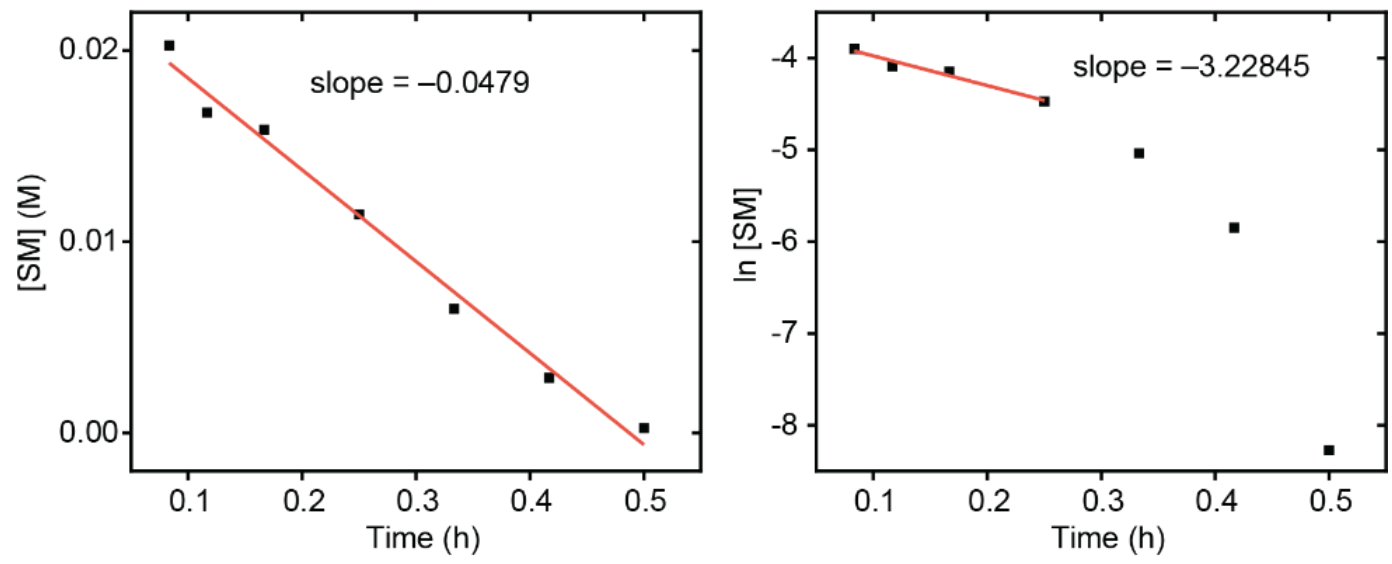

$10 \mathrm{~mol} \% \mathrm{Pd}_{3} \mathrm{Cu} / \mathrm{SiO}_{2}$ ( 3\% Pd Dispersion)
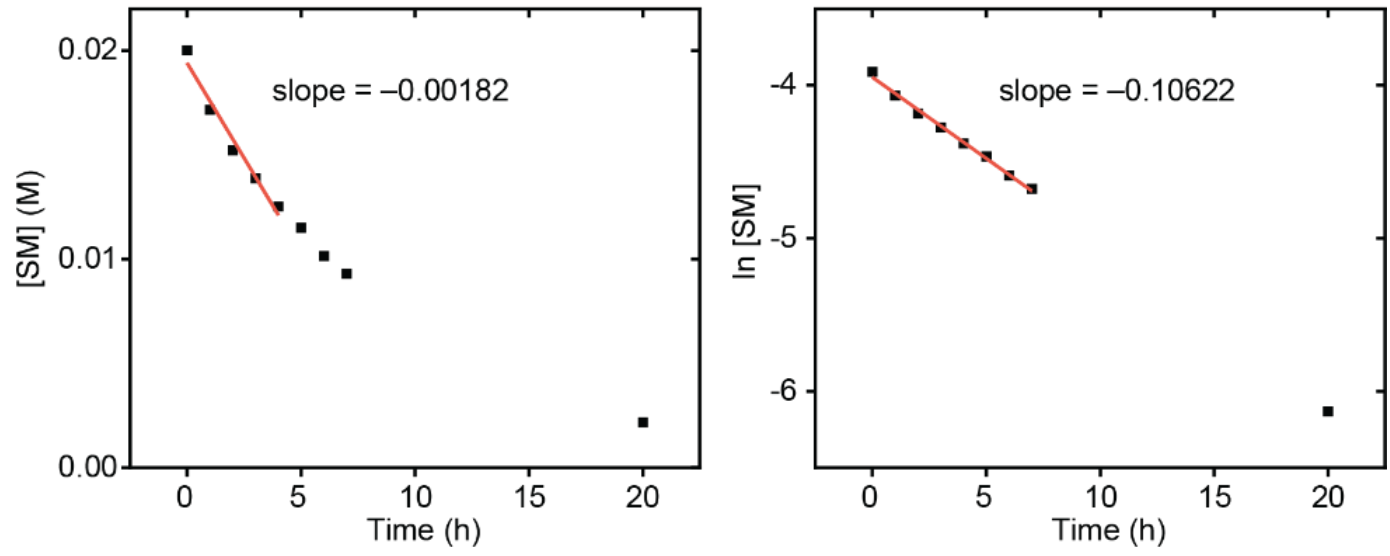

Figure S14. Kinetics for Crabtree's catalyst and $\mathrm{Pd}_{3} \mathrm{Cu} / \mathrm{SiO}_{2}$ in terpinen-4-ol hydrogenation.

Table S7. Kinetic parameters for Crabtree's catalyst and $\mathrm{Pd}_{3} \mathrm{Cu} / \mathrm{SiO}_{2}$.

\begin{tabular}{|l|l|l|l|l|}
\hline & \multicolumn{2}{|c|}{ Zero-order } & \multicolumn{2}{c|}{ First-order } \\
\hline & $k_{\text {obs }}\left(\mathrm{M} \mathrm{h}^{-1}\right)$ & $k_{\text {obs }} / \mathrm{mol}_{\mathrm{cat}}$ & $k_{\text {obs }}\left(\mathrm{h}^{-1}\right)$ & $k_{\text {obs }} / \mathrm{mol}_{\mathrm{cat}}$ \\
\hline Crabtree's cat $(2.5 \mathrm{~mol} \%)$ & 0.0479 & 95.8 & 3.23 & 6460 \\
\hline $\mathrm{Pd}_{3} \mathrm{Cu} / \mathrm{SiO}_{2}(10 \mathrm{~mol} \%)$ & 0.00182 & 30.3 & 0.106 & 1767 \\
\hline
\end{tabular}

$\mathrm{mol}_{\text {Ir }}=0.0005 \mathrm{M}$, mol PdSurf. $=0.00006 \mathrm{M}$ 

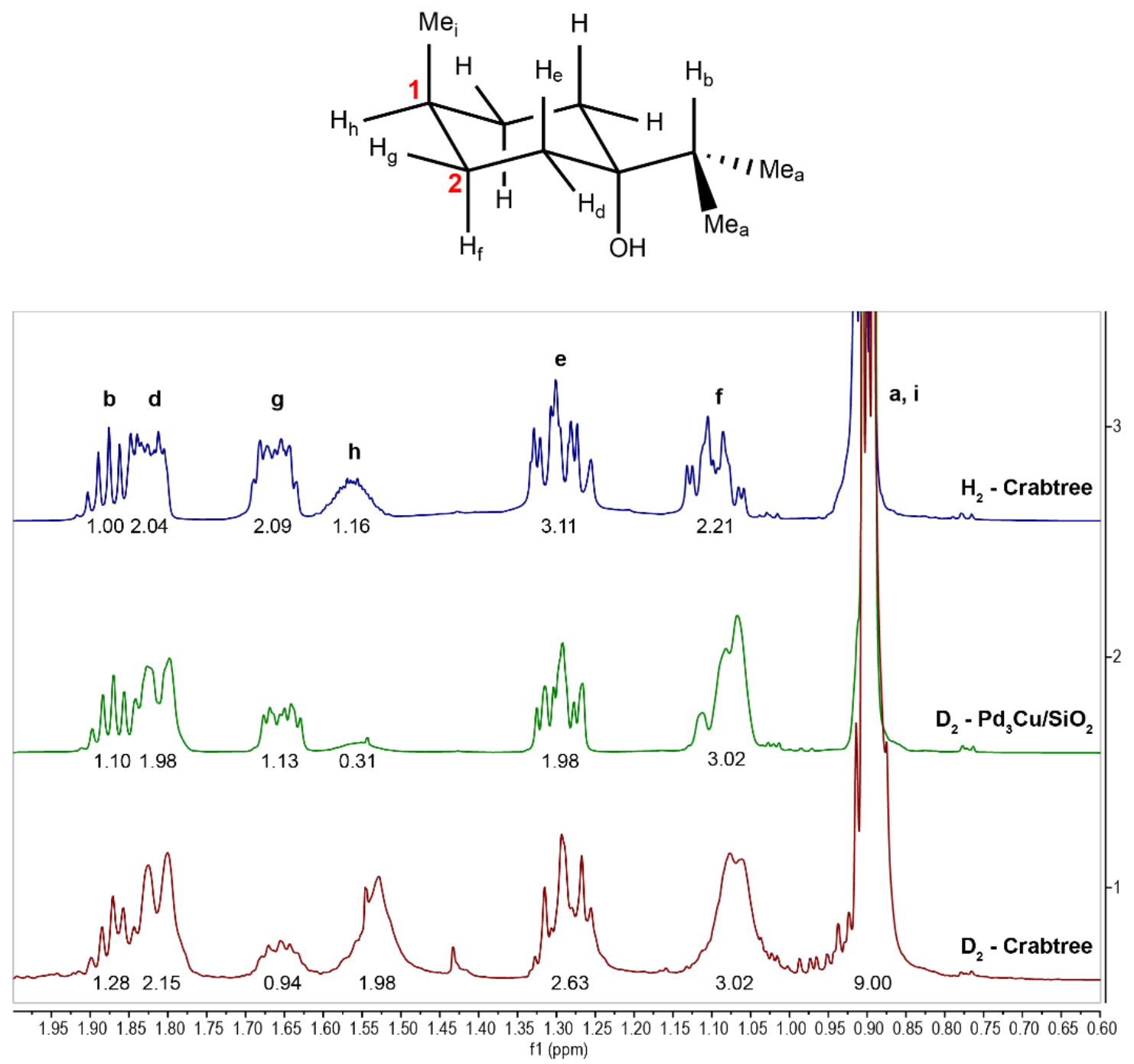

Figure S15. Overlay of product NMRs after $\mathrm{H}_{2}$ or $\mathrm{D}_{2}$ reaction of terpinen-4-ol over Crabtree's catalyst and $\mathrm{Pd}_{3} \mathrm{Cu} / \mathrm{SiO}_{2}$. 
Table S8. Solvent Screening on $\mathrm{Pd}$ and $\mathrm{Pd}_{3} \mathrm{Cu}$ Catalysts.*

\begin{tabular}{|c|c|c|c|c|}
\hline & Solvent & Time & Conversion & dr (P1:P2) \\
\hline \multirow{3}{*}{$\mathrm{Pd}_{3} \mathrm{Cu} / \mathrm{SiO}_{2}$} \\
\cline { 2 - 5 } & Ethanol & $20 \mathrm{~h}$ & 17 & $1: 1.5$ \\
\cline { 2 - 5 } $\mathrm{N}_{2}-400 \mathrm{H}_{2}$ & Ether & $20 \mathrm{~h}$ & 33 & $2.9: 1$ \\
\cline { 2 - 5 } & Dichloromethane & $20 \mathrm{~h}$ & 52 & $4.7: 1$ \\
\cline { 2 - 5 } & Cyclohexane (Std. Condition) & $20 \mathrm{~h}$ & $>99$ & $16: 1$ \\
\hline \multirow{3}{*}{$\mathrm{Pd} / \mathrm{SiO}_{2}$} & Ethanol & $20 \mathrm{~h}$ & $>99$ & $1: 6$ \\
\cline { 2 - 5 } & Ether & $20 \mathrm{~h}$ & $>99$ & $1: 3.8$ \\
\cline { 2 - 5 } & Dichloromethane & $20 \mathrm{~h}$ & $>99$ & $1: 1.3$ \\
\cline { 2 - 5 } & Hexanes & $20 \mathrm{~h}$ & $>99$ & $1: 2.5$ \\
\cline { 2 - 5 } & Cyclohexane (Std. Condition) & $20 \mathrm{~h}$ & $>99$ & $1: 1.7$ \\
\hline
\end{tabular}

*0.1 mmol terpinen-4-ol, 50 mg 2 wt.\% Pd catalyst, 5 mL solvent, $\mathrm{H}_{2}$ balloon, RT 
Table S9. Terpinen-4-ol hydrogenation reactivity for thermally-treated $\mathrm{Pd} / \mathrm{SiO}_{2}$ catalysts.

\begin{tabular}{|c|c|c|c|c|}
\hline & $\begin{array}{c}\text { Reduction } \\
\text { Temperature }\end{array}$ & Time & Conversion & $\mathrm{dr}(\mathrm{P} 1: \mathrm{P} 2)$ \\
\hline \multirow{3}{*}{$\mathrm{Pd} / \mathrm{SiO}_{2}$} & $\mathrm{~N} / \mathrm{A}$ & $20 \mathrm{~h}$ & $>99$ & $1: 1.7$ \\
\cline { 2 - 5 } & $200{ }^{\circ} \mathrm{C}$ & $20 \mathrm{~h}$ & $>99$ & $1: 2.1$ \\
\cline { 2 - 5 } & $400{ }^{\circ} \mathrm{C}$ & $20 \mathrm{~h}$ & $>99$ & $1: 1.9$ \\
\cline { 2 - 5 } & $800{ }^{\circ} \mathrm{C}$ & $20 \mathrm{~h}$ & $>99$ & $1: 1.0$ \\
\hline
\end{tabular}

a)

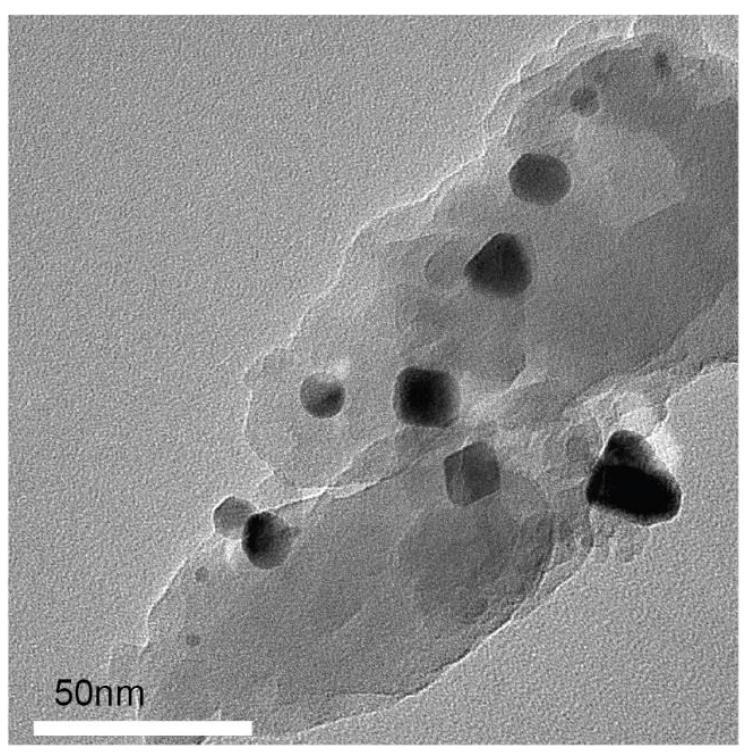

b)

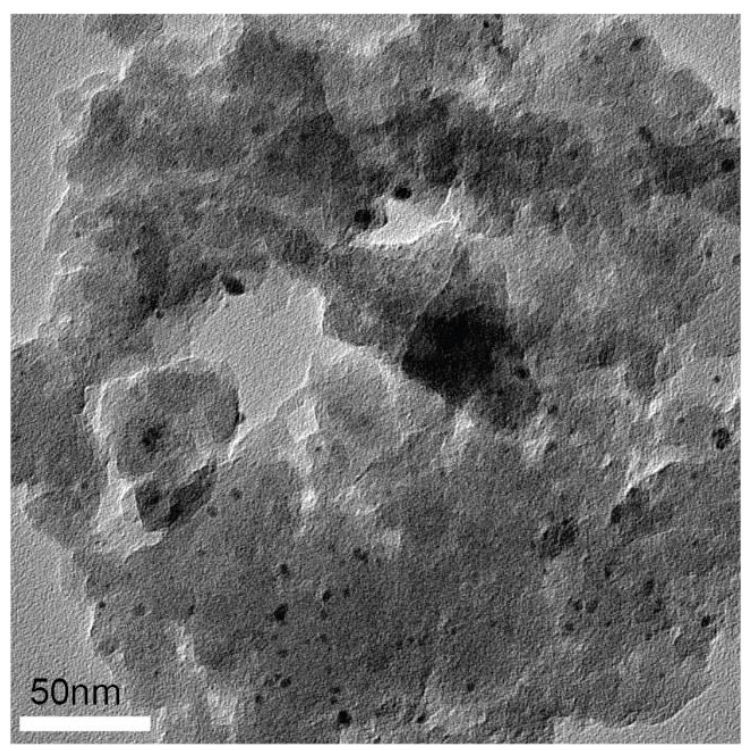

Figure S16. TEM images of $\mathrm{Pd} / \mathrm{SiO}_{2}$ reduced in $\mathrm{H}_{2}$ at (a) $800{ }^{\circ} \mathrm{C}$ or (b) $400{ }^{\circ} \mathrm{C}$. 

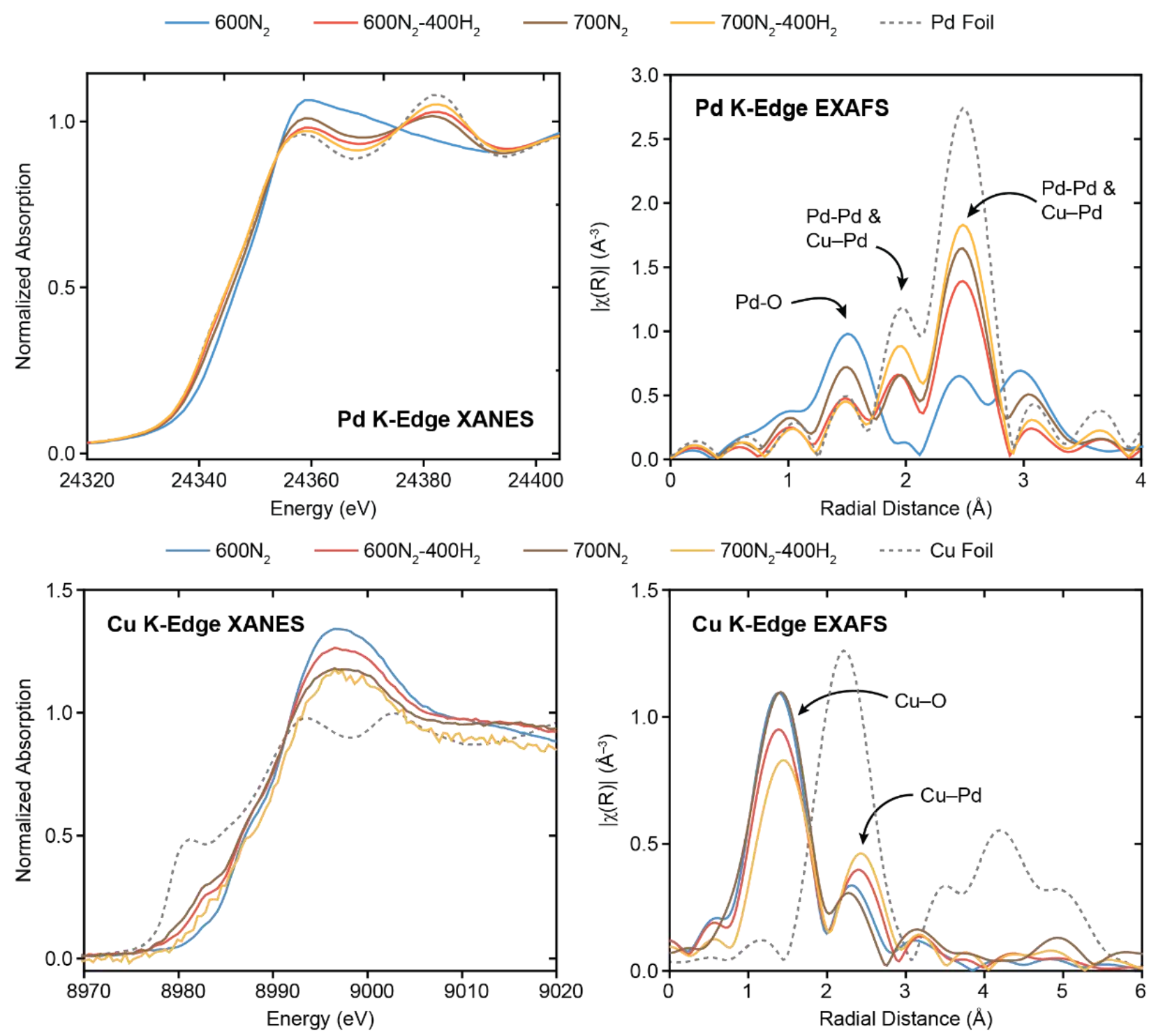

Figure S17. Pd K-edge and $\mathrm{Cu}$ K-edge XANES and EXAFS spectra for additional thermally annealed $\mathrm{Pd}_{3} \mathrm{Cu} / \mathrm{SiO}_{2}$ catalysts. 
Table S10. Pd K-edge and $\mathrm{Cu}$ K-edge EXAFS fitting parameters for additional thermally annealed $\mathrm{Pd}_{3} \mathrm{Cu} / \mathrm{SiO}_{2}$ catalysts.

\begin{tabular}{|c|c|c|c|c|c|c|}
\hline Sample & Edge & Scattering Pair & $\mathrm{CN}$ & $\mathrm{R}(\AA)$ & $\sigma^{2}\left(\AA^{2}\right)^{\mathrm{a}}$ & $\mathrm{E}_{0}(\mathrm{eV})$ \\
\hline \multirow{4}{*}{$\begin{array}{c}\mathrm{Pd}_{3} \mathrm{Cu} / \mathrm{SiO}_{2} \\
600{ }^{\circ} \mathrm{C} \mathrm{N}_{2}\end{array}$} & \multirow{2}{*}{$\mathrm{Pd}$} & $\mathrm{Pd}-\mathrm{O}$ & $3.5 \pm 0.2$ & $2.026 \pm 0.005$ & 0.002 & \multirow{2}{*}{$-1.0 \pm 0.6$} \\
\hline & & Pd-Pd & $1.4 \pm 0.3$ & $2.759 \pm 0.012$ & 0.005 & \\
\hline & \multirow{2}{*}{$\mathrm{Cu}$} & $\mathrm{Cu}-\mathrm{O}$ & $3.9 \pm 0.2$ & $1.905 \pm 0.005$ & \multirow{2}{*}{0.005} & \multirow{2}{*}{$-5.3 \pm 0.6$} \\
\hline & & $\mathrm{Cu}-\mathrm{Pd}$ & $1.0 \pm 0.3$ & $2.714 \pm 0.022$ & & \\
\hline \multirow{5}{*}{$\begin{array}{c}\mathrm{Pd}_{3} \mathrm{Cu} / \mathrm{SiO}_{2} \\
600{ }^{\circ} \mathrm{C} \mathrm{N}_{2}+400{ }^{\circ} \mathrm{C} \mathrm{H}_{2}\end{array}$} & \multirow{3}{*}{$\mathrm{Pd}$} & $\mathrm{Pd}-\mathrm{O}$ & $1.1 \pm 0.2$ & $1.983 \pm 0.014$ & 0.002 & \multirow{3}{*}{$-5.5 \pm 0.3$} \\
\hline & & $\mathrm{Pd}-\mathrm{Pd}$ & $6.8 \pm 0.2$ & \multirow{2}{*}{$2.723 \pm 0.002$} & \multirow{2}{*}{0.005} & \\
\hline & & $\mathrm{Pd}-\mathrm{Cu}$ & $0.8 \pm 0.2$ & & & \\
\hline & \multirow{2}{*}{$\mathrm{Cu}$} & $\mathrm{Cu}-\mathrm{O}$ & $3.1 \pm 0.2$ & $1.895 \pm 0.005$ & \multirow{2}{*}{0.005} & \multirow{2}{*}{$-6.4 \pm 0.6$} \\
\hline & & $\mathrm{Cu}-\mathrm{Pd}$ & $1.6 \pm 0.2$ & $2.699 \pm 0.011$ & & \\
\hline \multirow{4}{*}{$\begin{array}{c}\mathrm{Pd}_{3} \mathrm{Cu} / \mathrm{SiO}_{2} \\
700^{\circ} \mathrm{C} \mathrm{N}_{2}\end{array}$} & \multirow{2}{*}{$\mathrm{Pd}$} & $\mathrm{Pd}-\mathrm{O}$ & $1.8 \pm 0.1$ & $2.001 \pm 0.006$ & 0.002 & \multirow{2}{*}{$-4.8 \pm 0.2$} \\
\hline & & $\mathrm{Pd}-\mathrm{Pd}$ & $7.3 \pm 0.2$ & $2.747 \pm 0.002$ & 0.005 & \\
\hline & \multirow{2}{*}{$\mathrm{Cu}$} & $\mathrm{Cu}-\mathrm{O}$ & $3.8 \pm 0.3$ & $1.930 \pm 0.008$ & \multirow{2}{*}{0.005} & \multirow{2}{*}{$-0.5 \pm 0.9$} \\
\hline & & $\mathrm{Cu}-\mathrm{Pd}$ & $0.6 \pm 0.4$ & $2.747 \pm 0.067$ & & \\
\hline \multirow{4}{*}{$\begin{array}{c}\mathrm{Pd}_{3} \mathrm{Cu} / \mathrm{SiO}_{2} \\
700{ }^{\circ} \mathrm{C} \mathrm{N}_{2}+400{ }^{\circ} \mathrm{C} \mathrm{H}_{2}\end{array}$} & \multirow{2}{*}{$\mathrm{Pd}$} & $\mathrm{Pd}-\mathrm{Pd}$ & $9.2 \pm 0.3$ & \multirow{2}{*}{$2.727 \pm 0.002$} & \multirow{2}{*}{0.005} & \multirow{2}{*}{$-5.8 \pm 0.3$} \\
\hline & & $\mathrm{Pd}-\mathrm{Cu}$ & $1.0 \pm 0.3$ & & & \\
\hline & \multirow{2}{*}{$\mathrm{Cu}$} & $\mathrm{Cu}-\mathrm{O}$ & $2.9 \pm 0.2$ & $1.899 \pm 0.006$ & \multirow{2}{*}{0.005} & \multirow{2}{*}{$-5.9 \pm 0.5$} \\
\hline & & $\mathrm{Cu}-\mathrm{Pd}$ & $1.9 \pm 0.2$ & $2.697 \pm 0.009$ & & \\
\hline
\end{tabular}

${ }^{\mathrm{a}} \sigma^{2}$ values are determined based on metal foil references and fixed during the EXAFS fitting. 


\section{Cu K-Edge EXAFS}
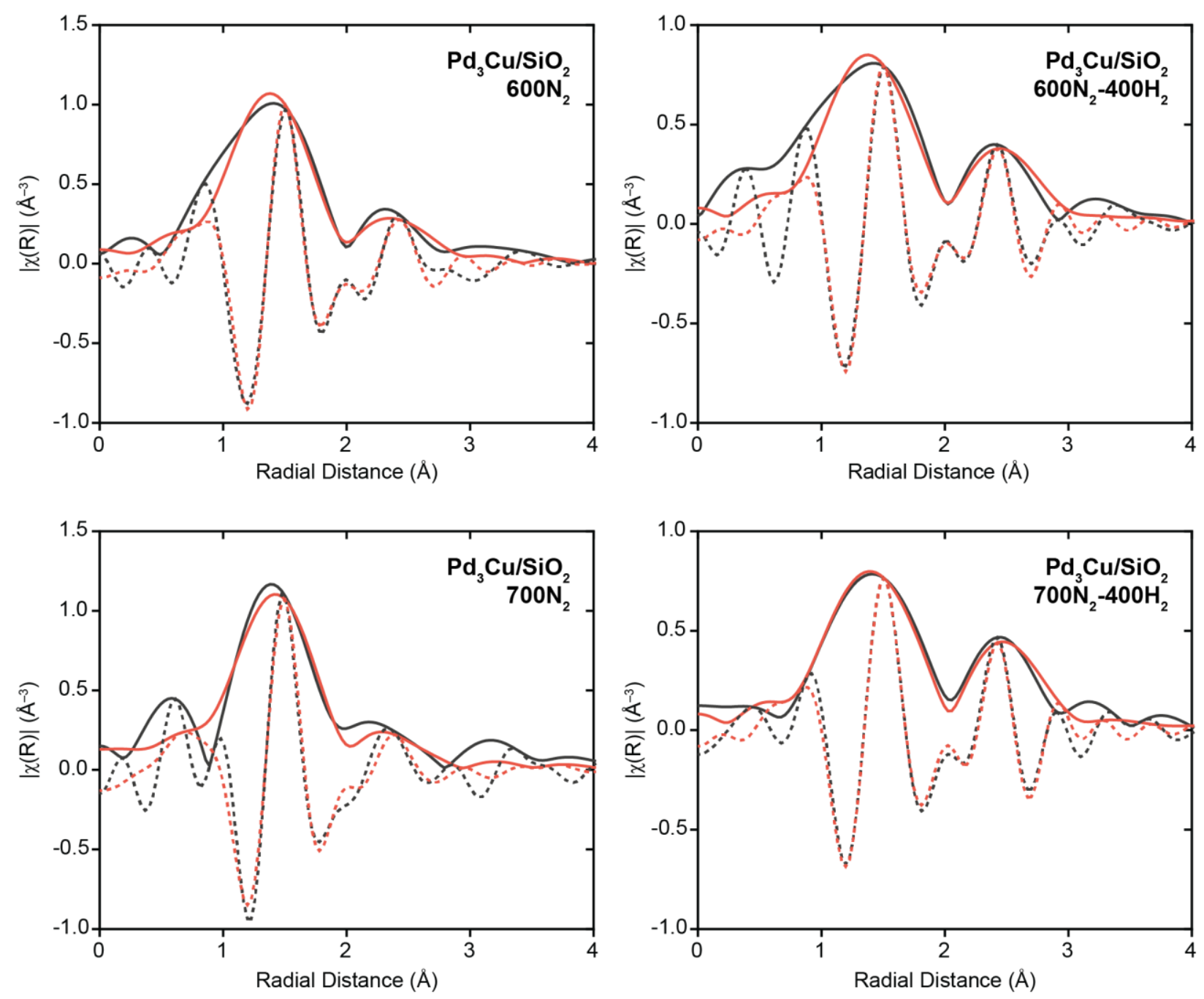

Figure S18. $\mathrm{Cu}$ K-edge EXAFS fitting results for additional thermally-treated $\mathrm{Pd}_{3} \mathrm{Cu} / \mathrm{SiO}_{2}$ samples. The black solid line is the FT magnitude, the red solid line is the fit to the FT magnitude, the black dotted line is the FT real part, and the red dotted line is the fit to the FT real part. 


\section{Pd K-edge EXAFS}
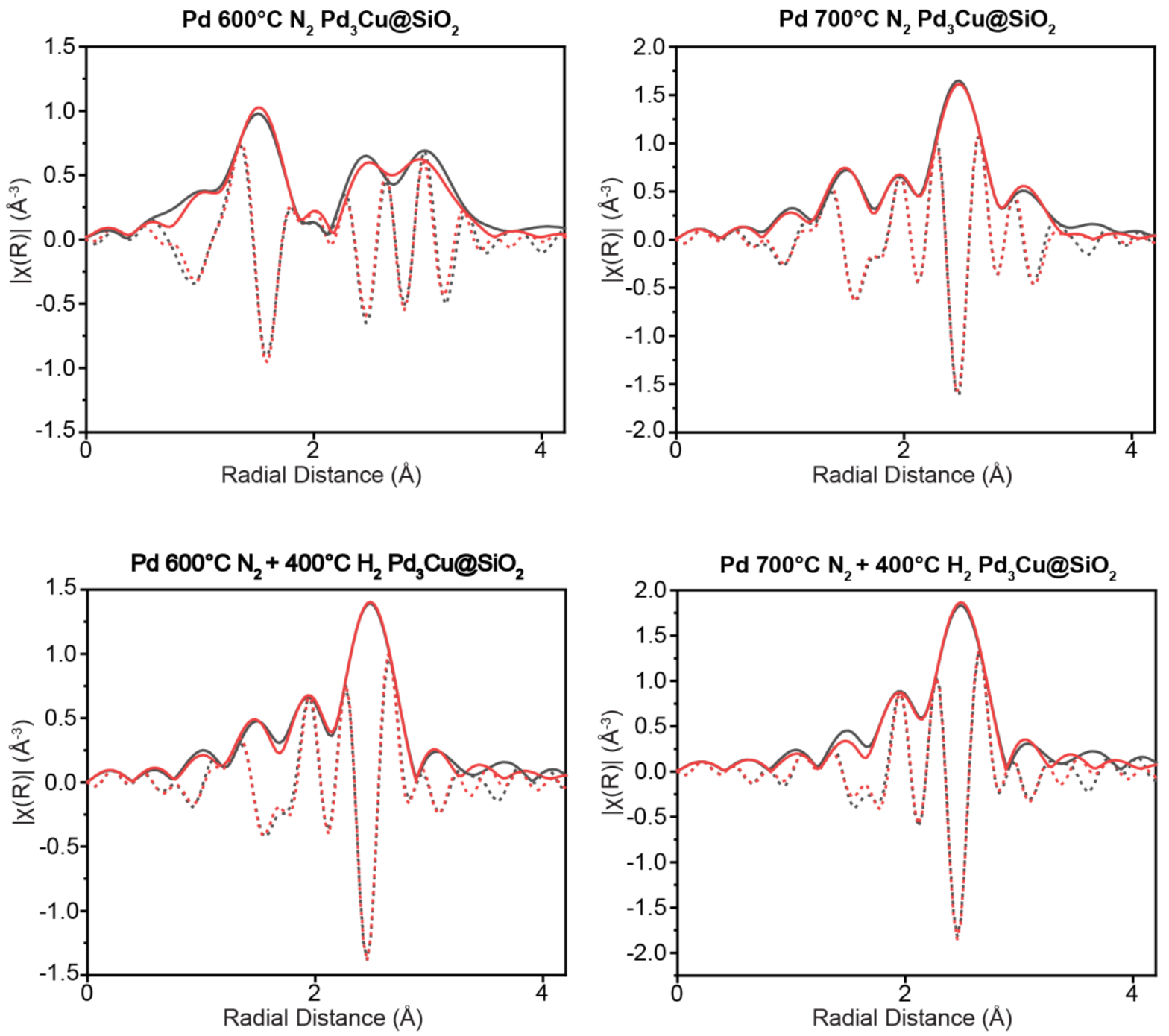

Figure S19. $\mathrm{Pd}$ K-edge EXAFS fitting results for additional thermally-treated $\mathrm{Pd}_{3} \mathrm{Cu} / \mathrm{SiO}_{2}$ samples. The black solid line is the FT magnitude, the red solid line is the fit to the FT magnitude, the black dotted line is the FT real part, and the red dotted line is the fit to the FT real part. 
Table S11. Reactivity comparison for $\mathrm{Pd}_{3} \mathrm{Cu} / \mathrm{SiO}_{2}$ with two different $\mathrm{SiO}_{2}$ pore sizes.
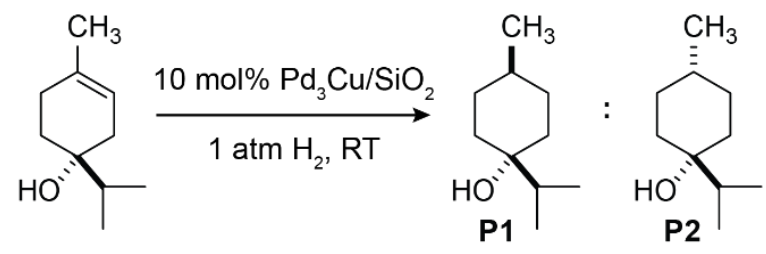

\begin{tabular}{rcrr}
\hline Catalyst & Time & Conversion & dr (P1:P2) \\
\hline $60 \AA \mathrm{SiO}_{2}$ & $12 \mathrm{~h}$ & $73 \%$ & $12: 1$ \\
$60 \AA \mathrm{SiO}_{2}$ & $20 \mathrm{~h}$ & $92 \pm 8 \%$ & $15 \pm 2: 1$ \\
$150 \AA \mathrm{SiO}_{2}$ & $12 \mathrm{~h}$ & $98 \%$ & $13: 1$ \\
$150 \mathrm{~A} \mathrm{SiO}_{2}$ & $20 \mathrm{~h}$ & $99 \pm 1 \%$ & $17 \pm 5: 1$ \\
\hline
\end{tabular}

a)

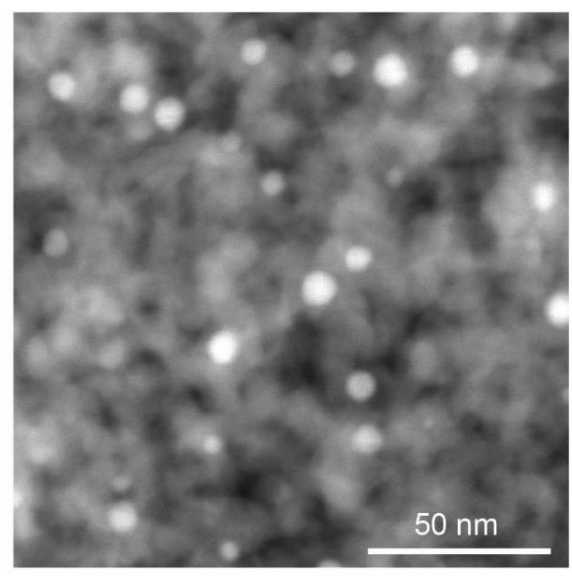

b)
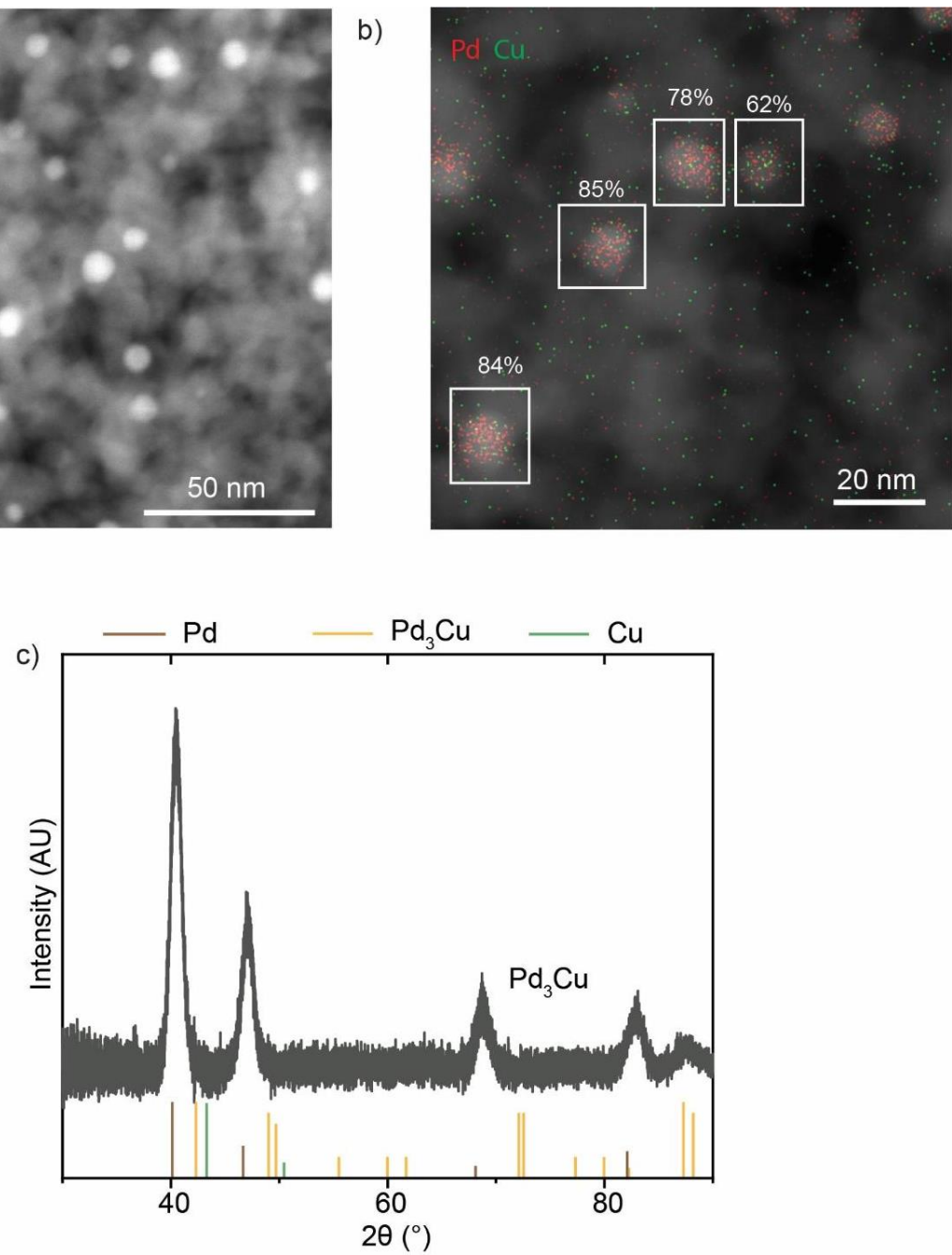

Figure S20. (a, b) STEM-EDS and (c) XRD characterization of a $\mathrm{Pd}_{3} \mathrm{Cu} / \mathrm{SiO}_{2}$ catalyst utilizing large pore $\mathrm{SiO}_{2}(150 \AA)$. 

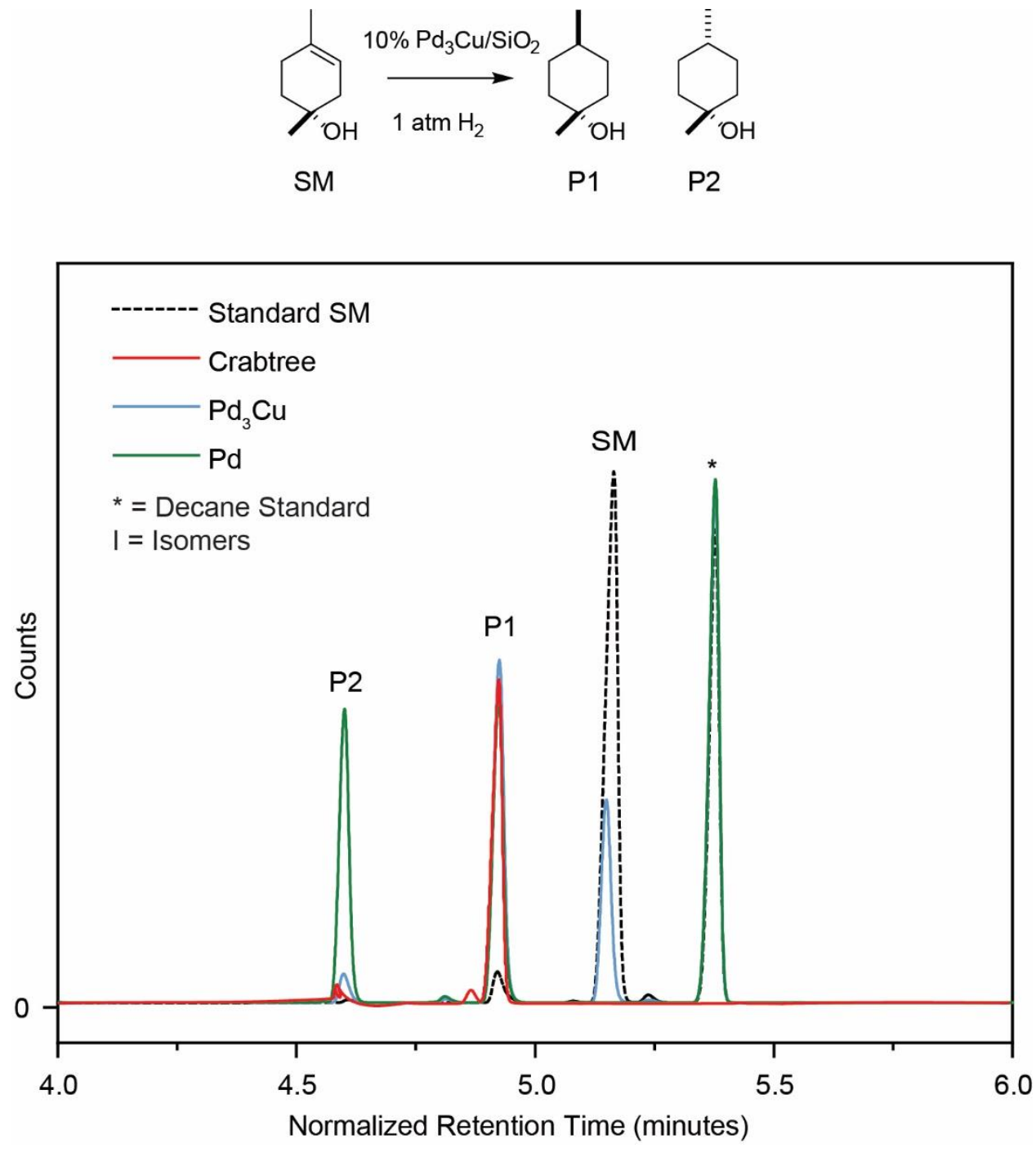

Figure S21. Crude reaction characterization for 1,4-dimethyl-3-cyclohexenol (Table 4, entry 2). Representative GC traces for the starting material standard and crude reactions using $\mathrm{Pd}_{3} \mathrm{Cu} / \mathrm{SiO}_{2}$, $\mathrm{Pd} / \mathrm{SiO}_{2}$, and $\left[\mathrm{Ir}(\mathrm{cod})\left(\mathrm{PCy}_{3}\right)(\mathrm{Py})\right] \mathrm{PF}_{6}($ Crabtree's catalyst $)$. 

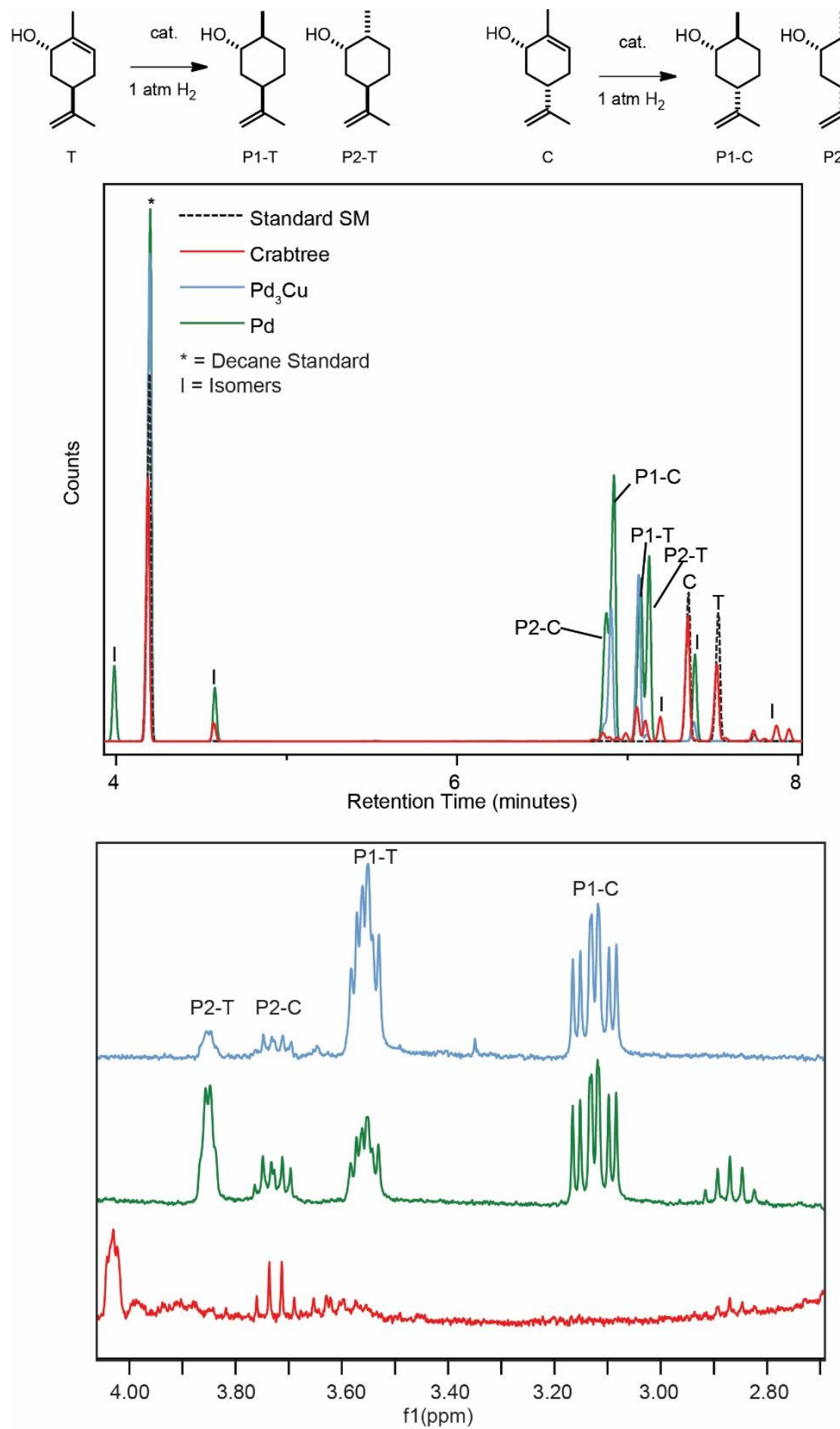

Figure S22. Crude reaction characterization for a mixture of cis- and trans-carveol (Table 4, entry 3, 4). Representative GC traces (top) and NMR spectra (bottom) for the starting material standard and crude reactions using $\mathrm{Pd}_{3} \mathrm{Cu} / \mathrm{SiO}_{2}, \mathrm{Pd} / \mathrm{SiO}_{2}$, and $\left[\mathrm{Ir}(\mathrm{cod})\left(\mathrm{PCy}_{3}\right)(\mathrm{Py})\right] \mathrm{PF}_{6}\left(\mathrm{Crabtree}^{\prime}\right.$ catalyst $)$. 

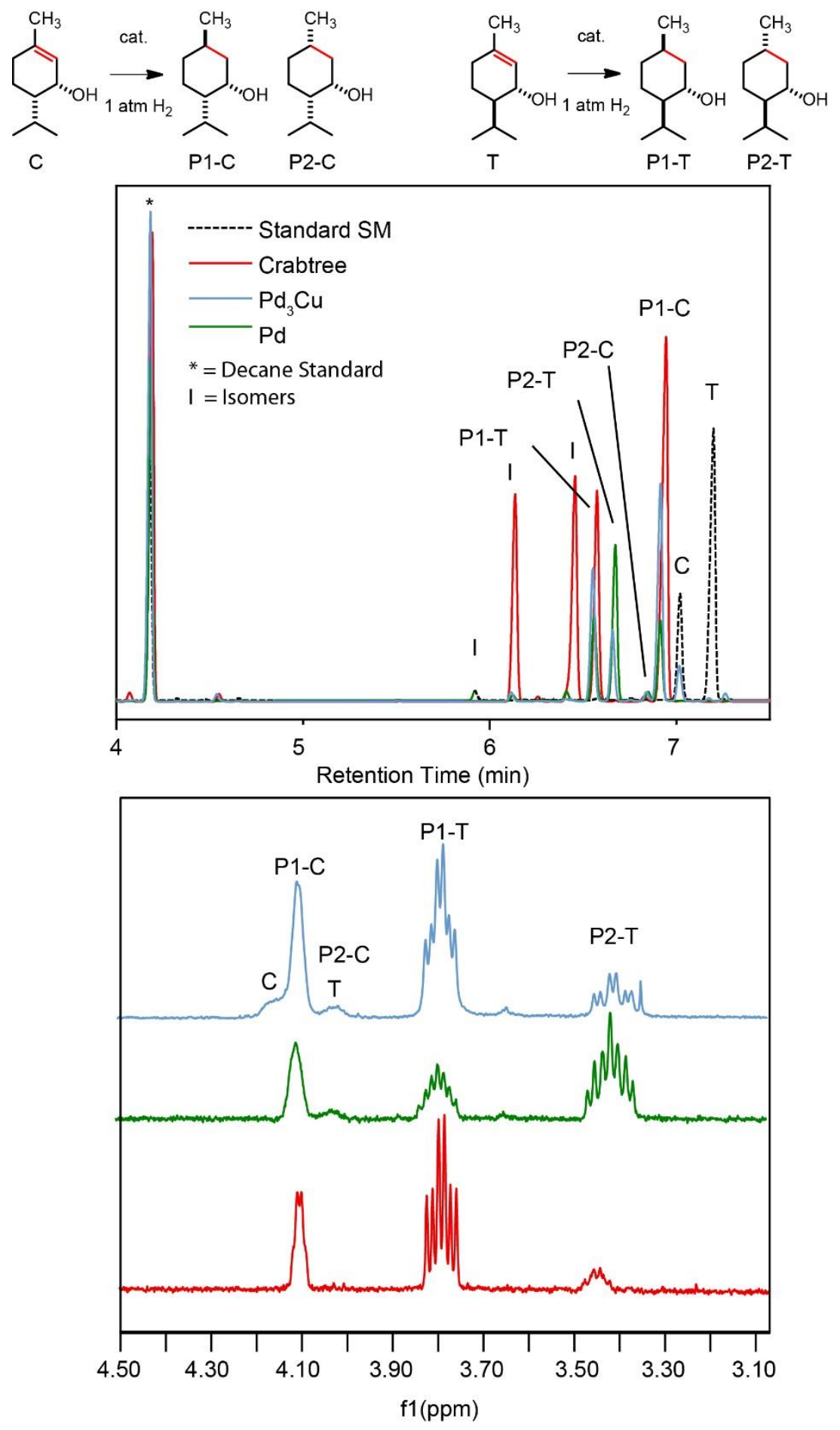

Figure S23. Crude reaction characterization for a mixture of cis- and trans-piperitol (Table 4, entry 5, 6). Representative GC traces (top) and NMR spectra (bottom) for the starting material standard and crude reactions using $\mathrm{Pd}_{3} \mathrm{Cu} / \mathrm{SiO}_{2}, \mathrm{Pd} / \mathrm{SiO}_{2}$, and $\left[\operatorname{Ir}(\operatorname{cod})\left(\mathrm{PCy}_{3}\right)(\mathrm{Py})\right] \mathrm{PF}_{6}(\mathrm{Crabtree} \mathrm{s}$ catalyst). 

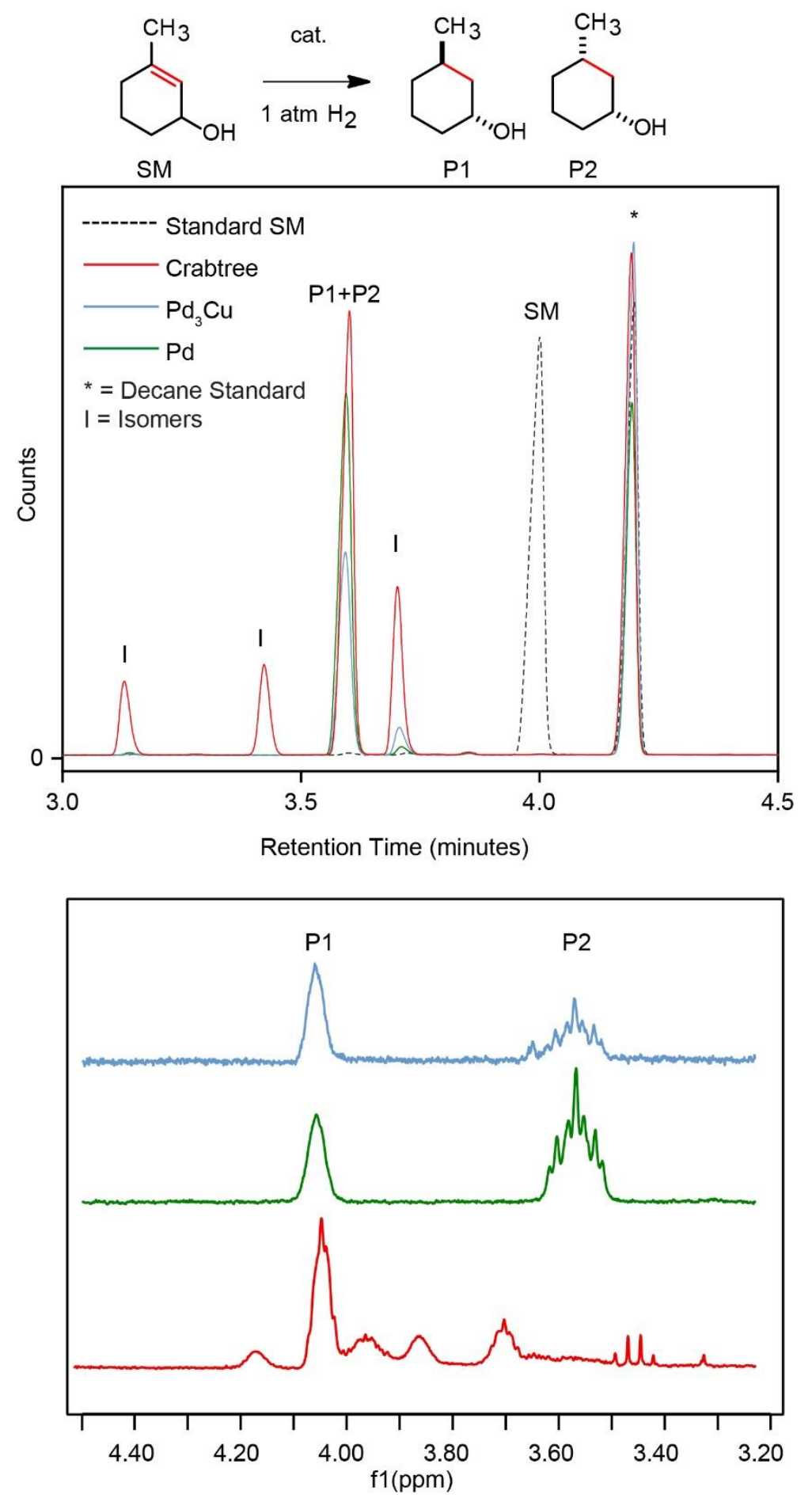

Figure S24. Crude reaction characterization for 3-methyl-2-cyclohexenol (Table 4, entry 7). Representative GC traces (top) and NMR spectra (bottom) for the starting material standard and crude reactions using $\mathrm{Pd}_{3} \mathrm{Cu} / \mathrm{SiO}_{2}, \mathrm{Pd} / \mathrm{SiO}_{2}$, and $\left[\mathrm{Ir}(\operatorname{cod})\left(\mathrm{PCy}_{3}\right)(\mathrm{Py})\right] \mathrm{PF}_{6}($ Crabtree's catalyst). 


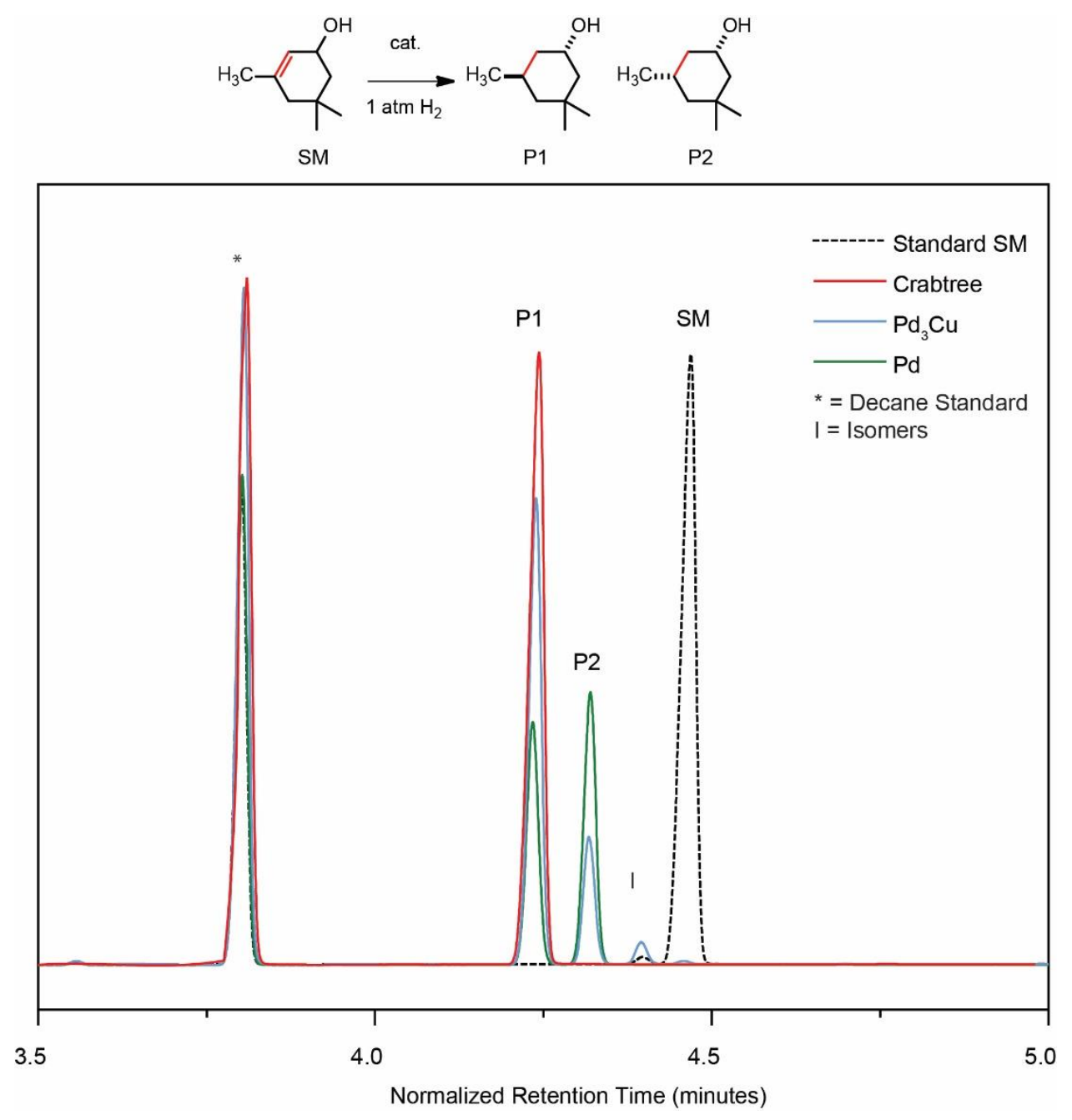

Figure S25. Crude reaction characterization for isophorol (Table 4, entry 8). Representative GC traces for the starting material standard and crude reactions using $\mathrm{Pd}_{3} \mathrm{Cu} / \mathrm{SiO}_{2}, \mathrm{Pd} / \mathrm{SiO}_{2}$, and $\left[\operatorname{Ir}(\operatorname{cod})\left(\mathrm{PCy}_{3}\right)\left(\mathrm{Py}_{2}\right)\right] \mathrm{PF}_{6}($ Crabtree's catalyst). 
Table S12. Reactivity of $\mathrm{Cu} / \mathrm{SiO}_{2}$ catalyst in terpinen-4-ol hydrogenation.*

\begin{tabular}{|c|c|c|c|}
\hline Catalyst & Time & Conversion & DR (P1:P2) \\
\hline $\mathrm{Cu} / \mathrm{SiO}_{2} \wedge$ & $20 \mathrm{~h}$ & 0 & $\mathrm{n} / \mathrm{a}$ \\
\hline
\end{tabular}

*0.1 mmol terpinen-4-ol, $50 \mathrm{mg} 2$ wt. $\% \mathrm{Cu} / \mathrm{SiO}_{2}$ catalyst, $5 \mathrm{~mL}$ cyclohexane, $\mathrm{H}_{2}$ balloon, $\mathrm{RT}$ ${ }^{\wedge} \mathrm{Cu} / \mathrm{SiO}_{2}$ catalyst reduced at $800{ }^{\circ} \mathrm{C}$ in $5 \% \mathrm{H}_{2}$ prior to use.

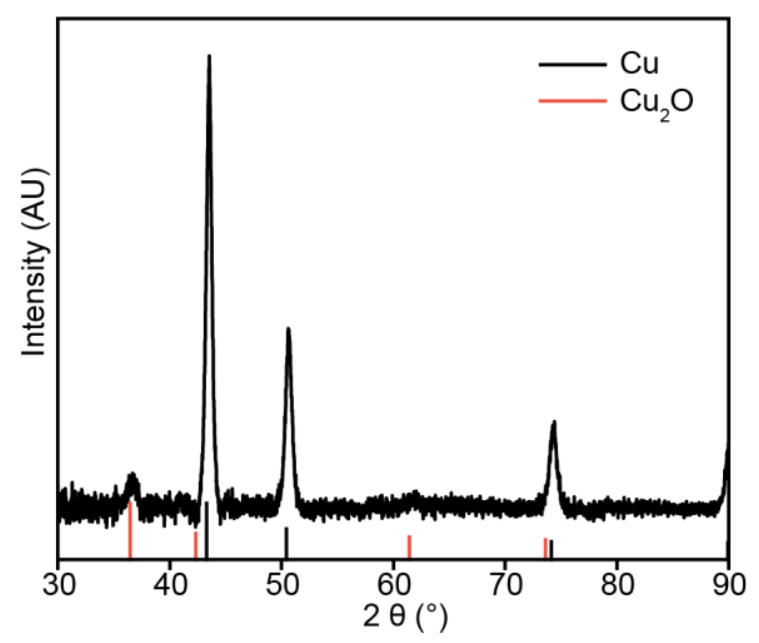

Figure S26. XRD pattern of $2 \mathrm{wt} . \% \mathrm{Cu} / \mathrm{SiO}_{2}$ catalyst reduced at $800{ }^{\circ} \mathrm{C}$ in $\mathrm{H}_{2}$. 
Table S13. Reactivity comparison for $\mathrm{Pd}_{3} \mathrm{Cu}$ nanoparticles supported on several metal oxides and carbon black.*

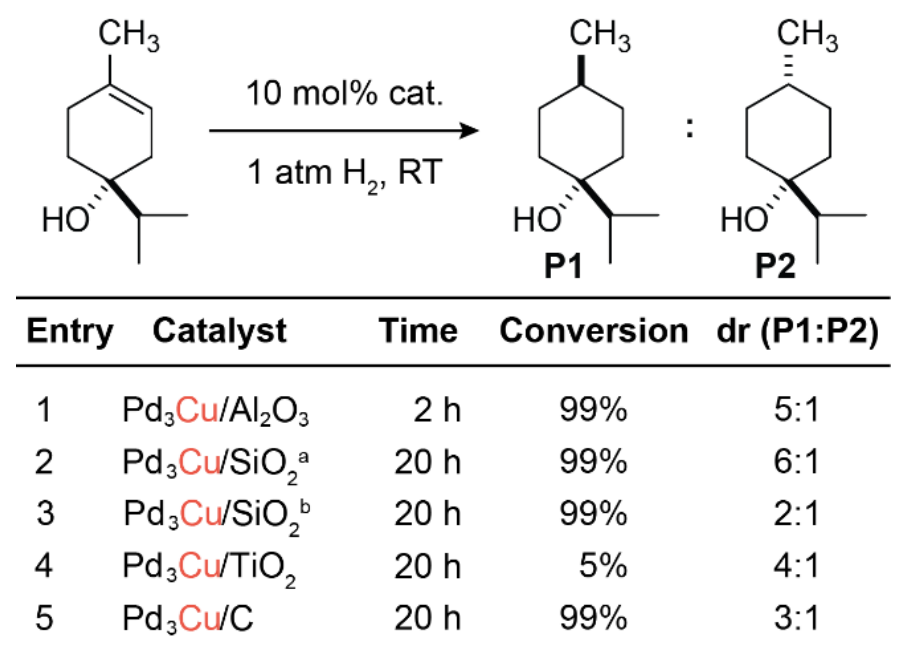

a35-60 mesh, $60 \AA ̊$ pore size,

b200-425 mesh, 60 A pore size

*All supported catalysts were prepared via co-impregnation of metal salts as described in the method for $\mathrm{Pd}_{3} \mathrm{M} / \mathrm{Al}_{2} \mathrm{O}_{3}$. Pd is loaded at $2 \mathrm{wt}$.\% on the metal oxides and $10 \mathrm{wt} . \%$ on C. 


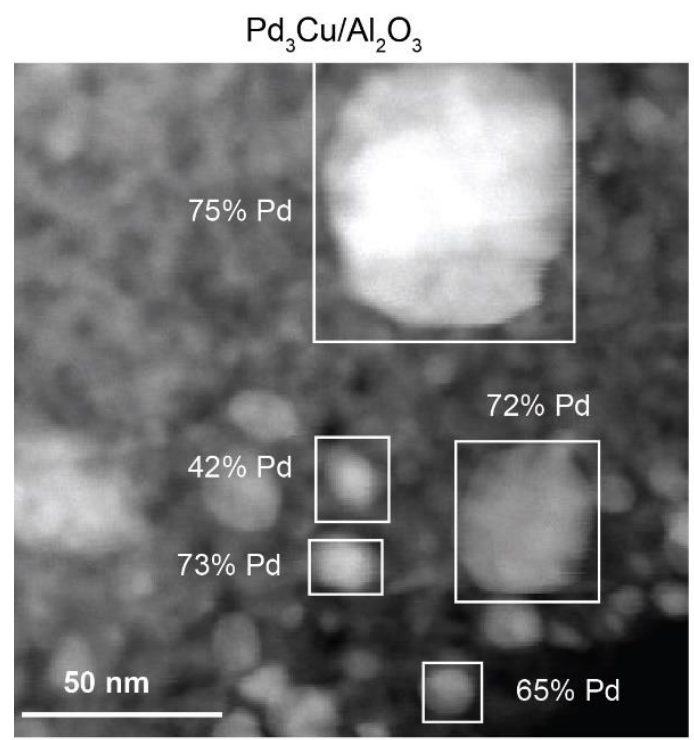

$\mathrm{Pd}_{3} \mathrm{Cu} / \mathrm{C}$

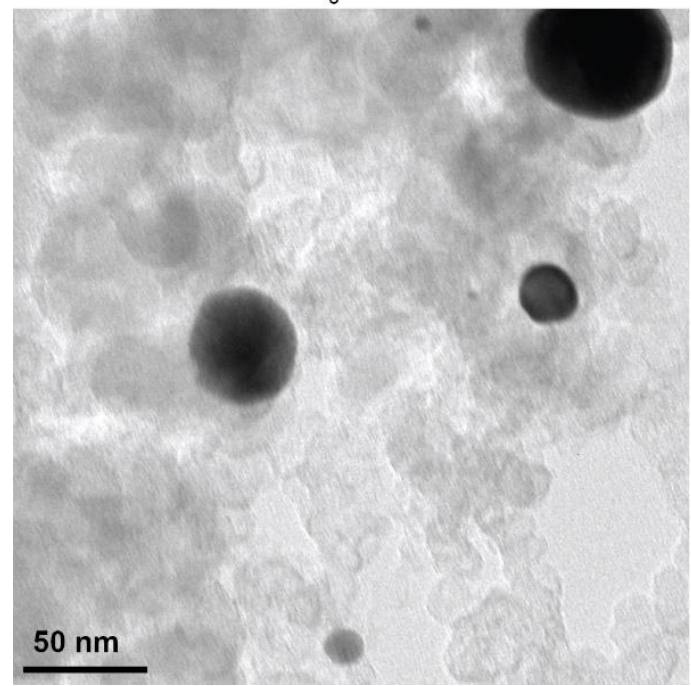

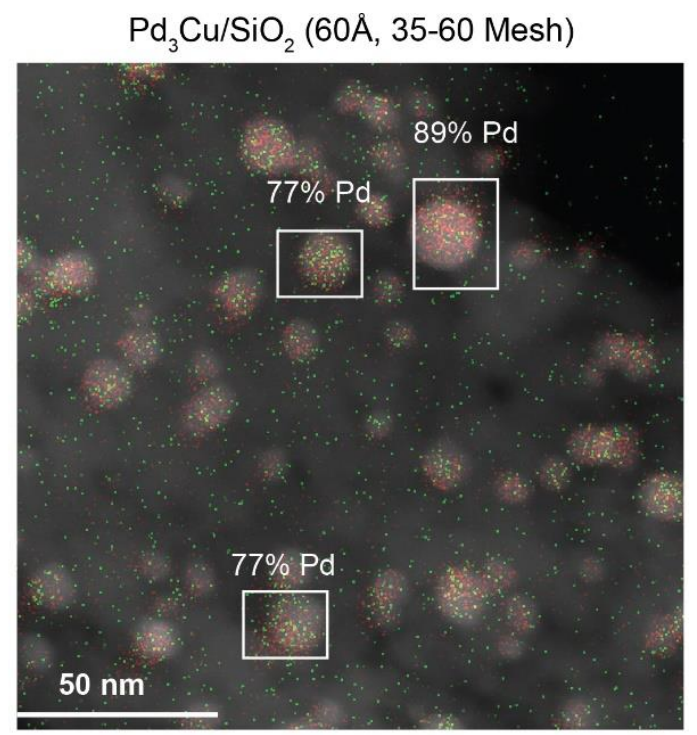

$\mathrm{Pd}_{3} \mathrm{Cu} / \mathrm{SiO}_{2}(60 \AA, 200-425 \mathrm{Mesh})$

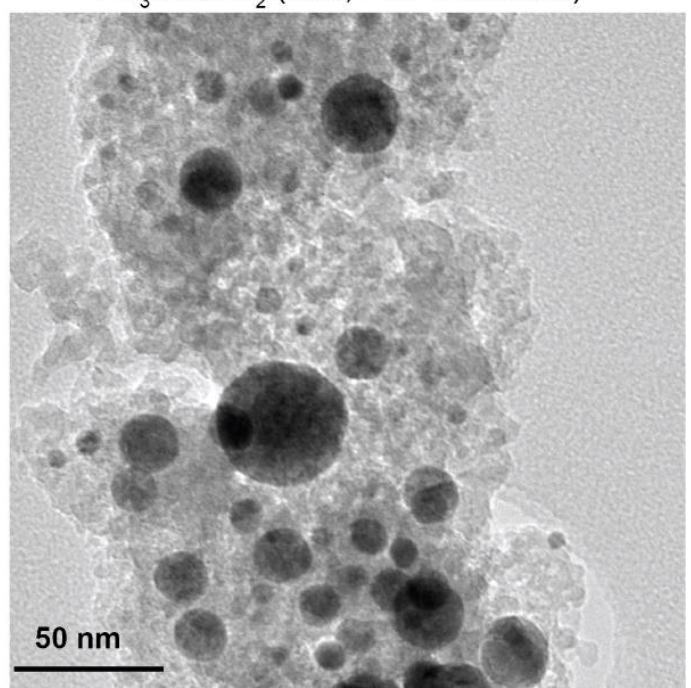

Figure S27. TEM and STEM-EDS data for $\mathrm{Pd}_{3} \mathrm{Cu}$ nanoparticles supported on variety of metal oxide and carbon supports. 


\section{References}

(1) Friedfeld, M. R.; Margulieux, G. W.; Schaefer, B. A.; Chirik, P. J. Bis(phosphine)cobalt Dialkyl Complexes for Directed Catalytic Alkene Hydrogenation. J. Am. Chem. Soc., 2014, 136, 13178-13181.

(2) Rubulotta, G.; Luska, K. L.; Urbina-Blanco, C. A.; Eifert, T.; Palkovits, R.; Quadrelli, E. A.; Thieuleux, C.; Leitner, W. Highly Selective Hydrogenation of R-(+)-Limonene to (+)p-1-Menthene in Batch and Continuous Flow Reactors. ACS Sustain. Chem. Eng., 2017, 5, 3762-3767.

(3) Bogel-Lukasik, E.; Bogel-Lukasik, R.; da Ponte, M. N. Pt- and Pd-catalysed limonene hydrogenation in high-density carbon dioxide. Monatsh. Chem., 2009, 140, 1361-1369.

(4) Engel, P. S.; Robertson, D. M.; Scholz, J. N.; Shine, H. J. Reaction of Azoalkanes with Isolable Cation Radical Salts. J. Org. Chem., 1992, 57, 6178-6187.

(5) Cantin, A.; Lull, C.; Primo, J.; Miranda, M. A.; Primo-Yufera, P. Isolation, structural assignment and insecticidal activity of (-)-(1S,2R,3R,4S)-1,2-epoxy-1-methyl-4-(1methylethyl)-cyclohex-3-yl acetate, a natural product from Minthostachys tomentosa. Tetrahedron Asymmetry, 2001, 12, 677-683.

(6) Masila, V. M.; Ndakala, A. J.; Byamukama, R.; Midiwo, J. O.; Kamau, R. W.; Wang, M.; Kumarihamy, M.; Zhao, J. P.; Heydreich, M.; Muhammad, I. Synthesis, structural assignments and antiinfective activities of 3-O-benzyl-carvotacetone and 3-hydroxy-2isopropyl-5-methyl-p-benzoquinone. Nat. Prod. Res., 2020.

(7) Jones-Mensah, E.; Nickerson, L. A.; Deobald, J. L.; Knox, H. J.; Ertel, A. B.; Magolan, J. Cerium-free Luche reduction directed by rehydrated alumina. Tetrahedron, 2016, 72, 37483753.

(8) Crabtree, R. H.; Davis, M. W. Directing Effects in Homogeneous Hydrogenation with $\left[\operatorname{Ir}(\operatorname{cod})\left(\mathrm{PCy}_{3}\right)(\mathrm{py})\right] \mathrm{PF}_{6}$. J. Org. Chem., 1986, 51, 2655-2661.

(9) Decouzon, M.; Géribaldi, S.; Rouillard, M.; Sturla, J. M. A new look at the spectroscopic properties of dihydrocarveol stereoisomers. Flavour Fragr. J., 1990, 5, 147-152.

(10) Wishart, D. S.; Knox, C.; Guo, A. C.; Eisner, R.; Young, N.; Gautam, B.; Hau, D. D.; Psychogios, N.; Dong, E.; Bouatra, S.; Mandal, R.; Sinelnikov, I.; Xia, J. G.; Jia, L.; Cruz, J. A.; Lim, E.; Sobsey, C. A.; Shrivastava, S.; Huang, P.; Liu, P.; Fang, L.; Peng, J.; Fradette, R.; Cheng, D.; Tzur, D.; Clements, M.; Lewis, A.; De Souza, A.; Zuniga, A.; Dawe, M.; Xiong, Y. P.; Clive, D.; Greiner, R.; Nazyrova, A.; Shaykhutdinov, R.; Li, L.; Vogel, H. J.; Forsythe, I. HMDB: a knowledgebase for the human metabolome. Nucleic Acids Res., 2009, 37, D603-D610.

(11) Canton, P.; Fagherazzi, G.; Battagliarin, M.; Menegazzo, F.; Pinna, F.; Pernicone, N. $\mathrm{Pd} / \mathrm{CO}$ average chemisorption stoichiometry in highly dispersed supported $\mathrm{Pd} /$ gamma$\mathrm{Al}_{2} \mathrm{O}_{3}$ catalysts. Langmuir, 2002, 18, 6530-6535.

(12) Ravel, B.; Newville, M. ATHENA, ARTEMIS, HEPHAESTUS: data analysis for X-ray absorption spectroscopy using IFEFFIT. J. Synchrotron Radiat., 2005, 12, 537-541. 